\title{
Promotional effects of nitrogen doping on catalytic performance over manganese- containing semi-coke catalysts for the NH3-SCR at low temperatures
}

Yao, Lu; Liu, Qingcai; Mossin, Susanne; Nielsen, David; Kong, Ming; Jiang, Lijun; Yang, Jie; Ren, Shan; Wen, Juan

Published in:

Journal of Hazardous Materials

Link to article, DOI:

10.1016/j.jhazmat.2019.121704

Publication date:

2020

Document Version

Peer reviewed version

Link back to DTU Orbit

Citation (APA):

Yao, L., Liu, Q., Mossin, S., Nielsen, D., Kong, M., Jiang, L., Yang, J., Ren, S., \& Wen, J. (2020). Promotional effects of nitrogen doping on catalytic performance over manganese-containing semi-coke catalysts for the NH3SCR at low temperatures. Journal of Hazardous Materials, 387, [121704].

https://doi.org/10.1016/j.jhazmat.2019.121704

\section{General rights}

Copyright and moral rights for the publications made accessible in the public portal are retained by the authors and/or other copyright owners and it is a condition of accessing publications that users recognise and abide by the legal requirements associated with these rights.

- Users may download and print one copy of any publication from the public portal for the purpose of private study or research.

- You may not further distribute the material or use it for any profit-making activity or commercial gain

- You may freely distribute the URL identifying the publication in the public portal 


\section{Journal Pre-proof}

Promotional effects of nitrogen doping on catalytic performance over manganese-containing semi-coke catalysts for the $\mathrm{NH}_{3}-\mathrm{SCR}$ at low temperatures

Lu Yao (Conceptualization)

(Methodology)<ce:contributor-role>Writing - Original draft)

(Investigation) (Formal analysis), Qingcai Liu (Supervision)

(Methodology) (Resources) (Funding acquisition), Susanne Mossin

(Methodology) (Resources) (Writing - review and editing), David

Nielsen (Investigation) (Visualization), Ming Kong (Validation)

(Writing - review and editing), Lijun Jiang (Investigation) (Formal

analysis) (Validation), Jie Yang (Investigation) (Formal analysis)

(Writing - review and editing), Shan Ren (Conceptualization)

(Funding acquisition) (Project administration), Juan Wen

(Resources) (Investigation) (Writing - review and editing)

PII:

S0304-3894(19)31658-9

DOI:

https://doi.org/10.1016/j.jhazmat.2019.121704

Reference:

HAZMAT 121704

To appear in:

Journal of Hazardous Materials

Received Date:

6 August 2019

Revised Date:

15 November 2019

Accepted Date:

15 November 2019

Please cite this article as: Yao L, Liu Q, Mossin S, Nielsen D, Kong M, Jiang L, Yang J, Ren S, Wen J, Promotional effects of nitrogen doping on catalytic performance over manganese-containing semi-coke catalysts for the $\mathrm{NH}_{3}$-SCR at low temperatures, Journal of Hazardous Materials (2019), doi: https://doi.org/10.1016/j.jhazmat.2019.121704 
This is a PDF file of an article that has undergone enhancements after acceptance, such as the addition of a cover page and metadata, and formatting for readability, but it is not yet the definitive version of record. This version will undergo additional copyediting, typesetting and review before it is published in its final form, but we are providing this version to give early visibility of the article. Please note that, during the production process, errors may be discovered which could affect the content, and all legal disclaimers that apply to the journal pertain.

(C) 2019 Published by Elsevier. 
Promotional effects of nitrogen doping on catalytic performance over manganesecontaining semi-coke catalysts for the $\mathrm{NH}_{3}-\mathrm{SCR}$ at low temperatures

Lu Yao a, b, Qingcai Liu ${ }^{\text {a }}{ }^{*}$, Susanne Mossin ${ }^{\text {b, * }}$, David Nielsen ${ }^{\text {b }}$, Ming Kong a, b, Lijun Jiang a , Jie Yang a, Shan Ren ${ }^{\mathrm{a},{ }^{*}, \text { Juan Wen }}{ }^{\mathrm{a}, \mathrm{c}}$

${ }^{a}$ College of Materials Science and Engineering, Chongqing University, Chongqing, 400044,

\section{China}

${ }^{b}$ Department of Chemistry, Technical University of Denmark, Lyngby, 2800, Denmark

${ }^{c}$ Chongqing Cheng Tou Road and Bridge Administration Co. Ltd, Chongqing, 400060, China

* corresponding author email: liu_qingcai@163.com (Qingcai Liu)

slmo@kemi.dtu.dk (Susanne Mossin)

shan.ren@cqu.edu.cn(Shan Ren)

\section{Graphical Abstract}

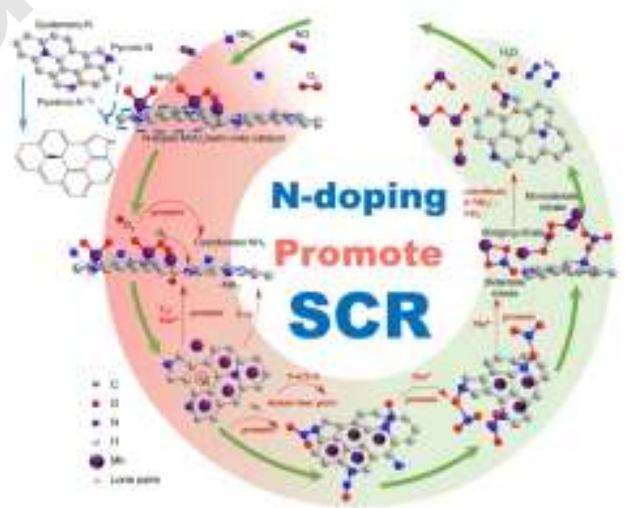




\section{Highlights}

- Nitrogen doping results in the appearance of pyridinic-N, pyrrolic-N and quaternary-N over the semi-coke catalyst.

- Nitrogen doping enhances the electron donor effect and electron mobility of the catalyst to improve the adsorption of NO.

- The intermediates formed by $\mathrm{N}$-doping promote coordinated $\mathrm{NH}_{3}$ and $-\mathrm{NH}_{2}$ species to further participate in LT SCR reaction.

- ASC-10U10Mn catalyst exhibits the best catalytic performance for $\mathrm{LT} \mathrm{NH}_{3}-\mathrm{SCR}$ reaction.

\section{Abstract}

A series of nitrogen-doped $\mathrm{MnO}_{x} /$ semi-coke catalysts were studied for low-temperature (LT) de- $\mathrm{NO}_{x}$ performance in the $\mathrm{NH}_{3}-\mathrm{SCR}$ reaction. Changes in morphology, structure, and surface chemistry of the semi-coke catalysts were systematically investigated to analyze the promotional effects of nitrogen doping on catalytic performance. The catalytic activity of ASC$10 \mathrm{U} 10 \mathrm{Mn}$ was found to be enhanced significantly in a broad temperature range of $100-300^{\circ} \mathrm{C}$, improving $44.2 \%$ at $150^{\circ} \mathrm{C}$ - the largest jump in this temperature range-and reaching $94.5 \%$ at $275^{\circ} \mathrm{C}$. Nitrogen doping results in aromatic pyridinic-N, pyrrolic-N, and quaternary-N; the unpaired electrons on these groups play a critical role in enhancing the adsorption and oxidation of $\mathrm{NO} . \mathrm{NH}_{3}$ adsorption is enhanced due to numerous diverse Lewis acid sites on ASC$10 \mathrm{U} 10 \mathrm{Mn}$. The electron distribution of $\mathrm{MnO}_{x} /$ semi-coke catalysts and the electron mobility between manganese and oxygen species are improved by nitrogen doping. The resulting nitrate intermediates, especially bridging nitrates, can be reduced by $\mathrm{NH}_{3}$ species at low temperatures. The increase in the number of oxygen vacancies improves oxidation of coordinated $\mathrm{NH}_{3}$. In addition, DRIFTS results suggest that coordinated $\mathrm{NH}_{3}$ and intermediate $-\mathrm{NH}_{2}$ are much more active and make a considerable positive contribution to the LT SCR reaction. 


\section{Key words}

Nitrogen doping; $\mathrm{MnO}_{x} /$ semi-coke catalyst; Low-temperature SCR; Surface chemistry; Promotional mechanism

\section{Introduction}

Selective catalytic reduction (SCR) with ammonia is an effective technology to control nitrogen oxide pollution from stationary sources and a key part of this technology is the catalyst (Lu et al., 2018). Metallurgical industry is the second largest stationary emission source of nitrogen oxides after thermal power plants. Nevertheless, traditional $\mathrm{V}_{2} \mathrm{O}_{5}-\mathrm{WO}_{3}\left(\mathrm{MoO}_{3}\right) / \mathrm{TiO}_{2}$ catalysts are not applicable for de- $\mathrm{NO}_{x}$ of the low-temperature (usually below $300^{\circ} \mathrm{C}$ ) flue gas in the metallurgical industry, since catalysts have the optimum temperature range of $300-400^{\circ} \mathrm{C}$. In addition, the toxicity and high price of $\mathrm{V}_{2} \mathrm{O}_{5}-\mathrm{WO}_{3}\left(\mathrm{MoO}_{3}\right) / \mathrm{TiO}_{2}$ catalysts limit the application in other industrial fields (Fan et al., 2014; Li et al., 2017). Therefore, there is a high demand for an economical and eco-friendly catalyst system for de- $\mathrm{NO}_{x}$ at low temperatures.

The structural features and surface chemistry of catalyst support are important in new catalyst development, and they can affect the activity and stability of catalysts. Various carbon materials, such as activated carbon, activated carbon fibers, and activated coke/semi-coke, have drawn the researchers' attention for de- $\mathrm{NO}_{x}$ catalysis due to their low operating temperatures, regeneration capacity, and simplicity of modification (Shirahama et al., 2002; Zhu et al., 2000; Wang et al., 2014a; Jiang et al., 2019). As a byproduct of the metallurgical industry, semi-coke is both relatively inexpensive and accessible. From a material life-cycle perspective, it is also highly attractive to use semi-coke for catalyst preparation and thus integrate the recycling of solid 
waste with atmospheric pollution control (Knoblauch et al, 1981; Wang et al., 2017). Some researchers (Lu et al., 2018; Wang et al., 2014a; Ren et al., 2017) have verified that semi-coke is a promising catalyst support for $\mathrm{NH}_{3}-\mathrm{SCR}$ due to its superior de- $\mathrm{NO}_{x}$ performance. However, it remains challenging to further improve de- $\mathrm{NO}_{x}$ activity at low temperatures $\left(100-300^{\circ} \mathrm{C}\right)$.

In order to apply semi-coke to the large-scale treatment of LT flue gas, its surface chemistry must be modified in order to satisfy the conceived requirements of the catalytic reaction. One efficient modification method is to increase active sites by loading metal oxides, such as iron, cobalt, cerium, manganese, and lanthanum (Wang et al., 2017; Zhang et al., 2018; Yan et al., 2017). $\mathrm{MnO}_{x}$ catalysts exhibit excellent LT activity, but the differences in optimal performance among various catalysts, such as $\mathrm{MnO}_{x} / \mathrm{TiO}_{2}, \mathrm{MnO}_{x} / \mathrm{Al}_{2} \mathrm{O}_{3}$ or $\mathrm{MnO}_{x} /$ carbon nanotubes, are also noticeable (Fang et al., 2015; Yang et al., 2020; Wang et al. 2014c). Another modification method to improve catalytic activity is to introduce surface functionalities (Klinik et al., 2011). The intrinsic properties and concentrations of functional groups are important for catalyst performance. Nitrogen functional groups are particularly intriguing (Figueiredo et al., 2007). Watanabe et al. (Watanabe et al., 2015) discovered through theoretical investigations that nitrogen doping contributes to the interaction between carbon atoms at the edges of graphite and oxygen functional groups. Some researchers (Liang et al., 2018; He et al., 2016) revealed that doping nitrogen into $\mathrm{sp}^{2}$-hybridized carbon frameworks could alter the nature of carbon materials to enhance catalytic activity. Nitrogen doping is widely used in catalyst modification to improve the activity of catalytic oxidation, photocatalytic reactions and catalytic decomposition processes (Sousa et al., 2012; Zhao et al., 2017; Wang et al., 2018), but thus far there have been only a few studies on the nitrogen doping of $\mathrm{NH}_{3}$-SCR catalysts. 
Most research describes materials that have been modified in only one way, yet a few studies in the literature report combinations of the aforementioned methods on semi-coke to promote catalytic performance for $\mathrm{LT} \mathrm{NH}_{3}$-SCR reaction. Grzybek et al. (Grzybek et al., 2008) attempted to prepare activated carbon catalysts using combined modification methods, although further mechanisms were not reported. A semi-coke catalyst modified with melamine and $\mathrm{MnO}_{x}$ was prepared, and the improved SCR activity indicated a bright future for combined modification methods (Yao et al., 2019). Nonetheless, the role of nitrogen functional groups and the promotional mechanisms of nitrogen doping on the catalytic performance of $\mathrm{MnO}_{x} / \mathrm{semi}$-coke catalysts remain undefined.

In this work, a series of nitrogen-doped $\mathrm{MnO}_{x} /$ semi-coke catalysts were prepared and investigated for the $\mathrm{LT} \mathrm{NH}_{3}$-SCR performance. The physicochemical properties of the catalyst were systematically characterized by BET, SEM, XRD, XPS, $\mathrm{NH}_{3}-\mathrm{TPD}, \mathrm{H}_{2}-\mathrm{TPR}$ and in situ DRIFTS in order to determine the promotional effects of nitrogen doping on the catalytic performance and demonstrate the possible reaction path during the $\mathrm{LT} \mathrm{NH}_{3}-\mathrm{SCR}$ process.

\section{Experiments}

\subsection{Catalyst preparation}

Raw semi-coke in this work was obtained from Fugu, Shaanxi, China and its basic components are shown in Table 1. Before catalyst preparation, raw semi-coke was crushed and sieved into particles ranging 20-40 mesh and then pretreated in nitric acid solution (60 wt.\%) at $80^{\circ} \mathrm{C}$ for $3 \mathrm{~h}$. The pretreated semi-coke was washed with distilled water until washing water remained neutral and then dried fully at $100^{\circ} \mathrm{C}$. Activated semi-coke was obtained and marked 
as ASC.

\section{Table 1}

Proximate and elemental analysis results of semi-coke.

\begin{tabular}{cccccccccc}
\hline \multirow{2}{*}{ Sample } & \multicolumn{4}{c}{ Proximate analysis (\%) } & \multicolumn{4}{c}{ Elemental analysis (\%) } \\
\cline { 2 - 11 } & Moisture & Ash & Volatile & Fix carbon & C & H & O & N & S \\
\hline Semi-coke & 0.21 & 10.46 & 8.67 & 80.66 & 88.23 & 1.37 & 7.05 & 1.88 & 1.04 \\
\hline
\end{tabular}

A series of nitrogen-doped $\mathrm{MnO}_{x} /$ semi-coke catalysts were prepared by impregnation with a mixture of urea and $\mathrm{Mn}\left(\mathrm{CH}_{3} \mathrm{COO}\right)_{2} \cdot 4 \mathrm{H}_{2} \mathrm{O}$. The preparation process consisted of the following steps: (1) dissolving different relative amounts of urea and $\mathrm{Mn}\left(\mathrm{CH}_{3} \mathrm{COO}\right)_{2} \cdot 4 \mathrm{H}_{2} \mathrm{O}$ in distilled water while stirring; (2) adding ASC to above solution and sonicating for $30 \mathrm{~min}$, then continuing the stirring for $3 \mathrm{~h}$; (3) drying the samples at $100^{\circ} \mathrm{C}$ for $12 \mathrm{~h}$; (4) calcining the samples in $\mathrm{N}_{2}$ with a ramp of $2^{\circ} \mathrm{C} / \mathrm{min}$ to $400^{\circ} \mathrm{C}$ and maintaining $6 \mathrm{~h}$; and (5) cooling the calcined samples to room temperature in a $\mathrm{N}_{2}$ atmosphere. Nitrogen-doped $\mathrm{MnO}_{x} /$ semi-coke catalysts were thus obtained and denoted as ASC-x $y y \mathrm{Mn}$, in which $x$ and $y$ represent the mass loading amounts of urea and $\mathrm{MnO}_{x}$, respectively. The content of major elements in the semicoke catalysts was detected by ICP-OES (PerkinElmer Optima 8000) and elemental analysis, and the results are listed in Table 3 and Table 4.

\subsection{Catalytic performance measurements}

SCR activity measurements were carried out at atmospheric pressure in a fixed-bed quartz reactor of $10 \mathrm{~mm}$ inner diameter with $1 \mathrm{~g}$ catalyst under the following simulated reactant gas conditions: $0.05 \% \mathrm{NO}, 0.05 \% \mathrm{NH}_{3}, 5 \% \mathrm{O}_{2}, 0.01 \% \mathrm{SO}_{2}$ (when used), and $5 \% \mathrm{H}_{2} \mathrm{O}$ (when used) with $\mathrm{N}_{2}$ balance gas at a total flow of $500 \mathrm{~mL} / \mathrm{min}$, and GHSV $16000 \mathrm{~h}^{-1}$. The outlet 
concentrations of $\mathrm{NO}$ and $\mathrm{NO}_{2}$ were detected by an MRU OPTIMA7 (Germany) gas analyzer, and $\mathrm{N}_{2} \mathrm{O}$ was detected by a SinGoAn SGA-500B (China) $\mathrm{N}_{2} \mathrm{O}$ detector. The NO conversion and $\mathrm{N}_{2}$ selectivity were calculated using the following equations:

$$
\begin{gathered}
\text { NO conversion }(\%)=\frac{N O_{\text {in }}-N O_{\text {out }}}{N O_{\text {in }}} \times 100 \% \\
N_{2} \text { selectivity }(\%)=\left(1-\frac{2 N_{2} O_{\text {out }}+N O_{2 o u t}}{N O_{\text {in }}+N H_{3 i n}}\right) \times 100 \%
\end{gathered}
$$

Where the subscripts in and out represented the inlet and outlet concentration which were gathered after attaining steady state, respectively.

\subsection{Physical and chemical characterization}

Scanning electron microscope (SEM) analysis was conducted on a VEGA3 TESCAN with an accelerating voltage of $20 \mathrm{kV}$. Energy dispersive X-ray spectrometry (EDS) mapping was recorded to determine the content and distribution of elements. BET surface area of the samples was determined from $\mathrm{N}_{2}$ physisorption measurements on about $100 \mathrm{mg}$ sample at $77 \mathrm{~K}$ with a Micromeritics ASAP 2010 instrument. The sample was heated to $200^{\circ} \mathrm{C}$ for $1 \mathrm{~h}$ prior to the measurement.

X-ray diffraction (XRD) were performed on a Rigaku D/max-2500 powder diffractometer using $\mathrm{Cu} \mathrm{K \alpha}$ radiation $(\lambda=1.5418 \AA)$ at $40 \mathrm{kV}$ and $40 \mathrm{~mA}$ over the range of $10^{\circ} \leq 2 \theta \leq 90^{\circ}$. Crystalline phases were identified by comparison with the reference data from JCPDs.

X-ray photoelectron spectroscopy (XPS) were measured on a Thermo scientific system (ESCALAB 250Xi) at room temperature using $\mathrm{Al} \mathrm{K \alpha}$ radiation (1484.6 eV). Before acquisition of data, the sample was outgassed for $1 \mathrm{~h}$ in vacuum to minimize surface contamination. The spectra were deconvoluted using Avantage Data system software. 
$\mathrm{NH}_{3}$ temperature-programmed desorption $\left(\mathrm{NH}_{3}-\mathrm{TPD}\right)$ were conducted on a Micromeritics Autochem-II instrument. In each typical measurement, $150 \mathrm{mg}$ of dried sample was placed in a U-shaped quartz tube and pretreated in $50 \mathrm{~mL} / \mathrm{min} \mathrm{He}$ from room temperature to $300^{\circ} \mathrm{C}$ then cooled to $60^{\circ} \mathrm{C}$. The sample was then exposed to dry $\mathrm{NH}_{3}$ gas $\left(5 \% \mathrm{NH}_{3}\right.$ in $\left.\mathrm{He}\right)$ for $1 \mathrm{~h}$. After $\mathrm{NH}_{3}$ adsorption, the sample was flushed with $\mathrm{He}$ for $1 \mathrm{~h}$ at $60^{\circ} \mathrm{C}$. The TPD operation was conducted in $50 \mathrm{~mL} / \mathrm{min} \mathrm{He}$ from 60 to $700^{\circ} \mathrm{C}\left(10^{\circ} \mathrm{C} / \mathrm{min}\right)$.

$\mathrm{H}_{2}$ temperature-programmed reduction $\left(\mathrm{H}_{2}-\mathrm{TPR}\right)$ measurements were conducted on a Micromeritics Autochem-II instrument. In each typical measurement, $200 \mathrm{mg}$ of dried sample was placed in a $\mathrm{U}$-shaped quartz tube and pretreated in $50 \mathrm{~mL} / \mathrm{min} \mathrm{He}$ from room temperature to $200^{\circ} \mathrm{C}$ for $1 \mathrm{~h}$ and cooled to $60^{\circ} \mathrm{C}$. $\mathrm{H}_{2}$-TPR analysis was carried out in a reducing mixture (50 mL/min) consisting of $5 \% \mathrm{H}_{2}$ and balance Ar from 60 to $700^{\circ} \mathrm{C}\left(10^{\circ} \mathrm{C} / \mathrm{min}\right)$. The $\mathrm{H}_{2}$ concentration in the effluent stream was monitored by a thermal conductivity detector (TCD).

In situ diffuse reflectance infrared Fourier transform spectra (in situ DRIFTS) were collected from 700 to $4000 \mathrm{~cm}^{-1}$ by accumulating 64 scans with at a spectral resolution of $8 \mathrm{~cm}^{-1}$ on a Nicolet iS50 FTIR spectrometer equipped with an MCT detector cooled by liquid $\mathrm{N}_{2}$. Before each experiment, the sample was pretreated at $250^{\circ} \mathrm{C}$ for $2 \mathrm{~h}$ in $200 \mathrm{~mL} / \mathrm{min} \mathrm{He}$ and cooled to $200^{\circ} \mathrm{C}$. The background spectrum was collected in flowing He and automatically subtracted from the sample spectrum. The reaction conditions were controlled as follows: $0.12 \% \mathrm{NH}_{3}$, $0.12 \% \mathrm{NO}, 5 \% \mathrm{O}_{2}$ with $\mathrm{He}$ balance gas at a total flow of $200 \mathrm{~mL} / \mathrm{min}$. 


\section{Results and discussion}

\subsection{Catalytic performance}

Fig. 1(a) shows the de- $\mathrm{NO}_{x}$ performance of semi-coke catalysts with different $\mathrm{N}$-doping amount as a function of reaction temperature. ASC exhibited steady-state NO conversion of approximately $10 \%$ over the entire temperature range. Nitrogen-doped semi-coke catalysts displayed a sharp decrease followed by a moderate increase in NO conversion. A similar trend of NO conversion was also observed by Grzybek et al. (Grzybek et al., 2008) for nitrogendoped active carbon. ASC-5U exhibited the lowest $\mathrm{NO}$ conversion of $14.2 \%$ at $150^{\circ} \mathrm{C}$, for which increased nitrogen-doping induced a further decrease in NO conversion. Moreover, the conversion gaps among all the nitrogen-doped catalysts visibly increased above $175^{\circ} \mathrm{C}$.

Fig. 1(b) shows the de- $\mathrm{NO}_{x}$ performance of nitrogen-doped $\mathrm{MnO}_{x} /$ semi-coke catalysts as a function of reaction temperature. Loading $\mathrm{MnO}_{x}$ does indeed improve the $\mathrm{NO}$ conversion of the catalyst, as mentioned in the Introduction. Furthermore, after the nitrogen-doping of $\mathrm{MnO}_{x} /$ semi-coke catalysts, the $\mathrm{NH}_{3}$-SCR performance improves markedly in the range 100 $200^{\circ} \mathrm{C}$, especially at $150^{\circ} \mathrm{C}$, at which the increase of $\mathrm{NO}$ conversion achieved its maximum value of $44.2 \%$. The NO conversion was $48.3 \%$ for ASC-5U10Mn (blue in Fig. 1) and increased to $63.5 \%$ for $\mathrm{ASC}-10 \mathrm{U} 10 \mathrm{Mn}$ (pink) at $125^{\circ} \mathrm{C}$. With the increase of $\mathrm{N}$-doping, the $\mathrm{NO}$ conversion decreased to $59.8 \%$ for ASC-15U10Mn (orange). For ASC-10Mn (green), the NO conversion could only reach the same level when the reaction temperature was above $200^{\circ} \mathrm{C}$. ASC-10U10Mn exhibited the optimum NO conversion of $94.5 \%$ at $275^{\circ} \mathrm{C}$ and was effective in a broad temperature range of $100-300^{\circ} \mathrm{C}$. Specially, the NO conversion of ASC- $15 \mathrm{U} 10 \mathrm{Mn}$ was 
no longer increased with higher N-doping amount, which was close to that of ASC-10U10Mn below $200^{\circ} \mathrm{C}$. The NO conversion of ASC-15U10Mn, however, was obviously lower than that of ASC-10U10Mn as the reaction temperature was above $225^{\circ} \mathrm{C}$. And the conversion gap between nitrogen-doped $\mathrm{MnO}_{x} /$ semi-coke catalysts and ASC-10Mn diminishes within this reaction temperature range. Some researchers (Wang et al., 2012; Sun et al., 2017) also reported a similar trend above $250^{\circ} \mathrm{C}$ for $\mathrm{MnO}_{x} / \mathrm{MWCNTs}$ catalysts and bulk $\mathrm{MnO}_{x}$ catalysts.

The $\mathrm{N}_{2}$ selectivity of semi-coke catalysts were also measured and shown in Fig. S1. The $\mathrm{N}_{2}$ selectivity increased obviously under $175^{\circ} \mathrm{C}$ with $\mathrm{N}$-doping amount. Moreover, the $\mathrm{N}_{2}$ selectivity of ASC-10U10Mn could reach above $95 \%$ when the temperature was below $150^{\circ} \mathrm{C}$. Both of the improved NO conversion and $\mathrm{N}_{2}$ selectivity of ASC-10U10Mn demonstrated that N-doping could promote catalytic performance of ASC-10U10Mn.
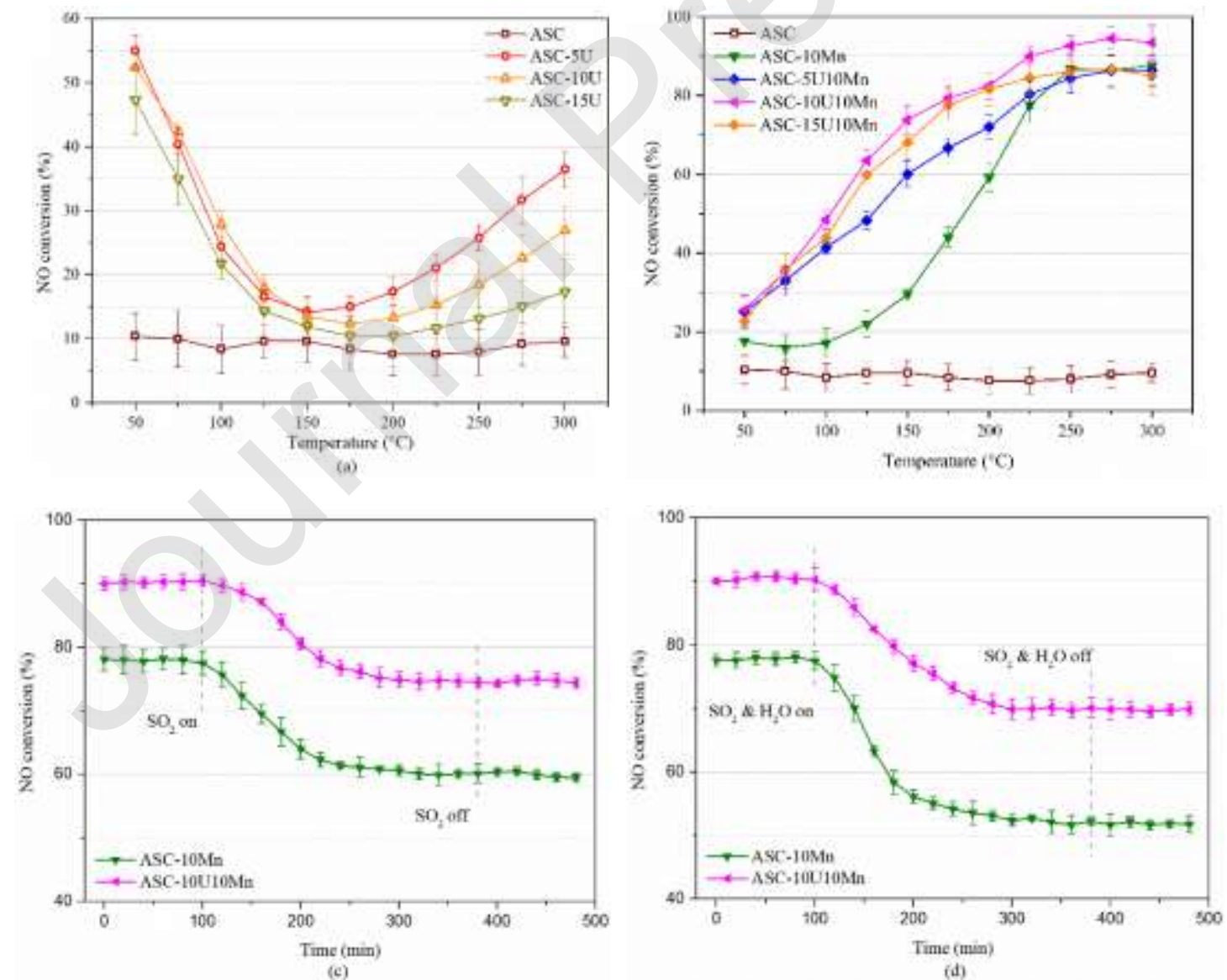
Fig.1 De-NO ${ }_{x}$ activity of (a) semi-coke catalysts with different N-doping amount; (b) nitrogen doped $\mathrm{MnO}_{x} /$ semi-coke catalysts; (c) ASC-10Mn and ASC-10U10Mn in the presence of $\mathrm{SO}_{2}$ at $225^{\circ} \mathrm{C}$; (d) ASC-10Mn and ASC-10U10Mn in the presence of $\mathrm{SO}_{2}+\mathrm{H}_{2} \mathrm{O}$ at $225^{\circ} \mathrm{C}$.

After the flue gas purification process of metallurgical industry, there is still a trace amount of $\mathrm{SO}_{2}$ (approximately $100 \mathrm{ppm}$ ) and $\mathrm{H}_{2} \mathrm{O}$ (approximately 5 vol\%). Therefore, the influences of $\mathrm{SO}_{2}$ and $\mathrm{H}_{2} \mathrm{O}$ on the de- $\mathrm{NO}_{x}$ activity of ASC-10Mn and ASC-10U10Mn were investigated, as shown in Fig. 1(c) and 1(d). Both ASC-10Mn and ASC-10U10Mn exhibited high NO conversion in the absence of $\mathrm{SO}_{2}$, although the $\mathrm{NO}$ conversion of ASC-10U10Mn was higher than that of ASC-10Mn. After introducing $\mathrm{SO}_{2}$, the NO conversion of ASC-10Mn decreased by approximately $17 \%$ from $77.6 \%$ in 180 min, and the NO conversion of ASC-10U10Mn dropped by approximately $14 \%$ from $90.0 \%$ in $200 \mathrm{~min}$. When $\mathrm{SO}_{2}$ was removed, ASC-10Mn and ASC10U10Mn barely recovered. After the simultaneous introduction of $\mathrm{SO}_{2}$ and $\mathrm{H}_{2} \mathrm{O}$, the deactivation of ASC-10Mn and ASC-10U10Mn was faster and more significant than those in the presence of $\mathrm{SO}_{2}$, indicating that the poisoning effects of $\mathrm{SO}_{2}$ and $\mathrm{H}_{2} \mathrm{O}$ on de- $\mathrm{NO}_{x}$ performance of semi-coke catalysts were stronger. Also, the inhibition effects of $\mathrm{SO}_{2}$ and $\mathrm{H}_{2} \mathrm{O}$ were irreversible.

3.2 Characterization of the catalysts

3.2.1 Morphology

SEM images revealed the extent of modification on semi-coke catalysts. As seen in Fig. 2, the surface of the raw semi-coke was relatively smooth, with no obviously developed pores. 
After pretreatment in nitric acid solution, the surface of the ASC was completely different from that of the raw semi-coke. Variably sized pores and laminar structures with ditches can be readily distinguished on ASC. These morphological changes are the result of nitric acid consuming volatile components in the semi-coke, thereby opening closed pores. A similar phenomenon has been noted in the literature for other carbon material-based catalysts ( $\mathrm{Su}$ et al., 2013; Chuang et al., 2011). The development of a porous structure provides more binding points between the support and $\mathrm{MnO}_{x}$ or doped nitrogen, indicating the necessity of pretreating the semi-coke with nitric acid.
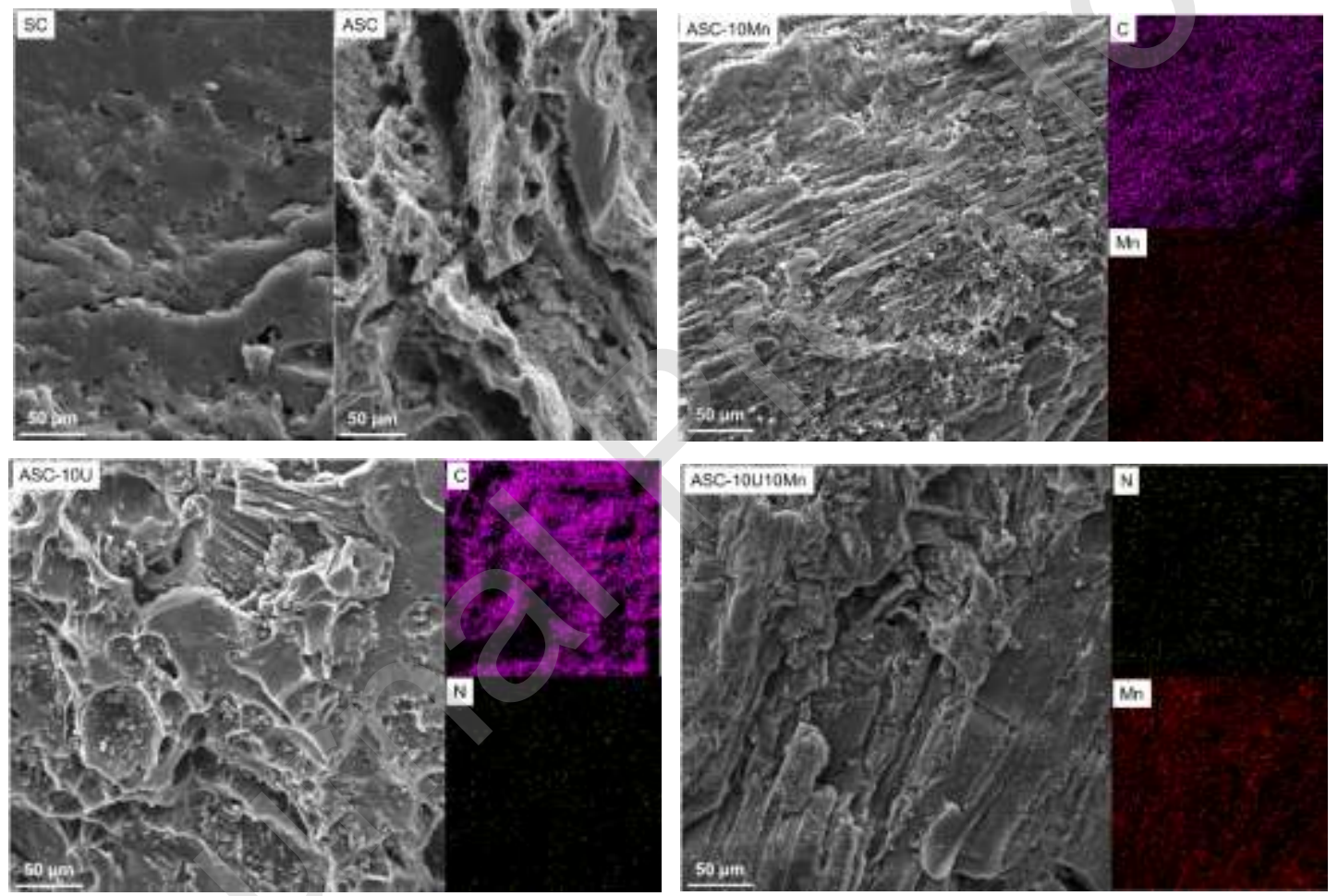

Fig. 2 SEM images of semi-coke catalysts and the corresponding elemental mapping by EDS

Compared with ASC, ASC-10Mn exhibited a much denser laminar structure and a mass of fine particles dispersed evenly in the ditches. This agrees with the EDS image of ASC-10Mn, which revealed the density of Mn to be sparse and even. ASC-10U exhibited a large number of 
net-like pores with much clearer flaky shapes. The density of nitrogen was scattered and indistinct in the EDS mapping of ASC-10U. Hence, it is difficult to estimate whether the morphology effects derived entirely from nitrogen doping. Notably, the morphology of ASC10U10Mn was completely different from that of other catalysts, retaining some net-like pores and presenting a distinct laminar structure. Although the manganese content of ASC-10U10Mn was almost the same as that of ASC-10Mn, as proved in Table 4, the Mn density was significantly higher at the corresponding positions of the ESD images, where the laminar structures were located. The distribution of nitrogen was more homogeneous and the density was higher on ASC-10U10Mn than on ASC-10U.

\subsubsection{Structural properties}

XRD measurements were conducted in order to study the crystallinity and dispersion of active phases on the catalysts. Fig. 3 compares the XRD patterns of manganese-containing catalyst samples to ASC before and after catalytic testing. There were 2 typical broad peaks at $24.6^{\circ}$ and $43.4^{\circ}$ in the XRD patterns of all the samples, which were both assigned to amorphous carbon (Gao et al., 2011; Prahas et al., 2008). The intensity of these peaks remained unchanged, suggesting that the carbon structure was undamaged. For ASC, weak diffraction peaks were observed at $20.8^{\circ}, 26.6^{\circ}, 36.5^{\circ}, 39.4^{\circ}, 50.0^{\circ}, 59.9^{\circ}$, and $68.4^{\circ}$. These were assigned to low $\mathrm{SiO}_{2}$ content in the ash of the semi-coke (Lu et al., 2018; Gao et al., 2011). Since $\mathrm{SiO}_{2}$ was unchanged during the modification and de- $\mathrm{NO}_{\mathrm{x}}$ catalysis process, the $\mathrm{SiO}_{2}$ diffraction peaks were present in the XRD patterns of all samples.

For fresh catalysts, peaks assigned to $\mathrm{MnO}_{2}$ at $35.1^{\circ}$ and $58.9^{\circ} ; \mathrm{Mn}_{3} \mathrm{O}_{4}$ at $36.1^{\circ}$ and $60^{\circ}$; and 
$\mathrm{MnO}$ at $40.7^{\circ}, 70.4^{\circ}$, and $73.9^{\circ}$ were found in all the XRD patterns (Fig. 3 and Fig.S2) (Wang et al., 2012; You et al., 2017; Wang et al., 2014d; Yang et al., 2017), demonstrating that $\mathrm{MnO}_{x}$ were successfully loaded on all the catalysts. An additional peak at $32.6^{\circ}$ in the patterns for ASC-5U10Mn and ASC-10U10Mn corresponded to $\mathrm{Mn}_{3} \mathrm{O}_{4}$. There was no obvious difference between the XRD patterns of ASC-5U10Mn and ASC-10U10Mn. Previous works (Fang et al., 2013; Kang et al., 2007) reported that a higher valence state of Mn was preferable for the redox property of $\mathrm{MnO}_{x} /$ catalysts in LT SCR reactions and $\mathrm{MnO}$ exhibited the poorest SCR activity among $\mathrm{MnO}_{x}$. This may explain the enhanced LT SCR activity of nitrogen-doped $\mathrm{MnO}_{x} /$ semicoke catalysts. In addition, structural defects induced by N-doping possibly facilitate the transition between $\mathrm{Mn}_{3} \mathrm{O}_{4}$ and $\mathrm{MnO}_{2}$, which provides more active oxygen sites.

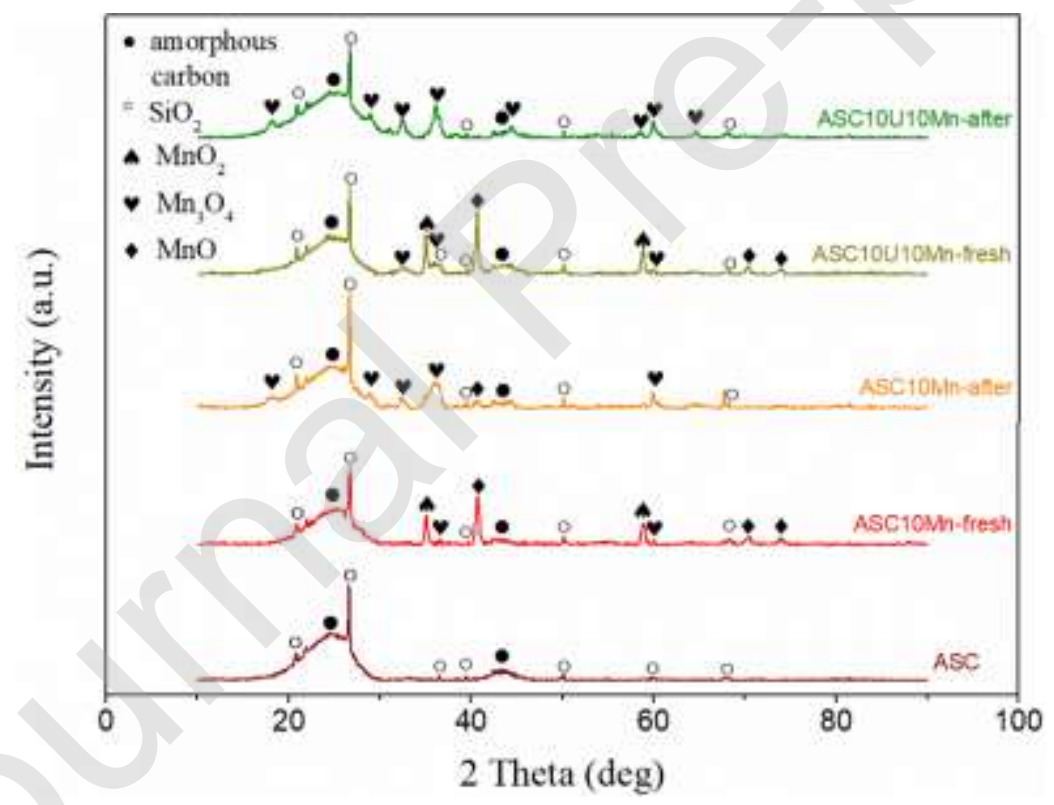

Fig.3 XRD patterns of semi-coke catalysts: (a) ASC, (b) ASC-10Mn, (c) ASC-10Mn-after, (d) ASC-10U10Mn, (e) ASC-10U10Mn-after

On the spent catalyst ASC-10Mn-after, the MnO peak was only observed at $40.7^{\circ}$ as shown in Fig. 3. The intensity of $\mathrm{MnO}$ peak changed obviously and the peak became invisible 
compared with the fresh catalysts. This suggests decreased crystal particle size and crystallinity degree of $\mathrm{MnO}$. All the peaks ascribed to $\mathrm{MnO}_{2}$ had disappeared. In ASC-10U10Mn-after, only the $\mathrm{Mn}_{3} \mathrm{O}_{4}$ peaks were observed. Based on the above comparisons of catalytic activity, the appearance of $\mathrm{Mn}_{3} \mathrm{O}_{4}$ had no negative impacts on the catalytic activity while $\mathrm{MnO}_{2}$ was consumed. Wang et al. (Wang et al., 2012) also observed that $\mathrm{Mn}_{3} \mathrm{O}_{4}$ had the same effect on other carbon-based catalysts. Additionally, there was no distinct diffraction peak assigned to $\mathrm{MnO}$ on ASC-10U10Mn-after, illustrating that $\mathrm{MnO}$ could become more dispersed during the SCR reaction.

3.2.3 BET surface areas and pore size distributions

Fig. 4 shows the nitrogen adsorption-desorption isotherms and pore size distributions of ASC, ASC-10Mn, ASC5U10Mn (Fig. S3) and ASC-10U10Mn. There are clear differences between the adsorption and desorption branches in the isotherms of all the catalysts. All the catalysts exhibit type IV isotherms with a type H4 hysteresis, indicating that the micropores, mesopores, and slit-pore structures present in semi-coke catalysts are in strong accordance with the SEM results. The pore distribution plots suggest that most pores are 3-4 nm, implying that semi-coke catalysts are typical mesoporous materials.
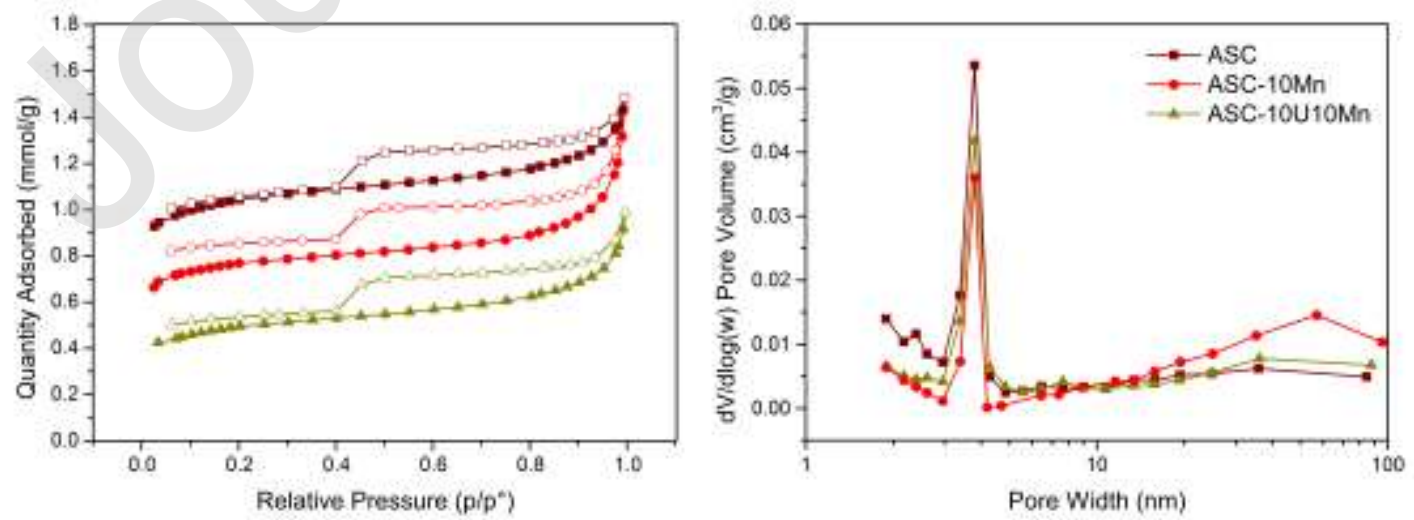
Fig. $4 \mathrm{~N}_{2}$ adsorption-desorption isotherms and pore distribution plots of semi-coke catalysts

\section{Table 2}

BET surface area and pore parameters of semi-coke catalysts.

\begin{tabular}{cccc}
\hline Sample & $\begin{array}{c}\text { BET surface area } \\
/ \mathrm{m}^{2} \cdot \mathrm{g}^{-1}\end{array}$ & $\begin{array}{c}\text { Average pore width } \\
/ \mathrm{nm}\end{array}$ & $\begin{array}{c}\text { Total pore volume } \\
/ \mathrm{cm}^{3} \cdot \mathrm{g}^{-1}\end{array}$ \\
\hline ASC & 79.2 & 6.0 & 0.044 \\
ASC-10Mn & 58.4 & 13.0 & 0.037 \\
ASC-10U10Mn & 38.0 & 8.2 & 0.026 \\
\hline
\end{tabular}

The data in Table 2 and Table S1 reveal significant differences in the BET surface area and pore parameters of ASC and semi-coke catalysts. Compared with ASC, semi-coke catalysts exhibit smaller BET surface area and total pore volume, and bigger average pore width. As manganese or nitrogen inserted into the pores or interlayers of ASC during the impregnation or calcination process, some pores were blocked or even collapsed, causing the BET surface area and total pore volume to decrease, and the average pore width to increase (Gao et al., 2018; Ruiz et al., 2008). When Mn-loading amounts were the same for the catalysts, BET surface area, average pore width and total pore volume would decrease with the $\mathrm{N}$-doping amount.

\subsubsection{XPS characterization}

XPS was used for investigating the identity and valence state of atoms on the surface of catalysts. The concentrations of oxygen, nitrogen, and manganese species were calculated and are summarized in Table 3 and Table 4. Figs. 5(a), (c), and (e) show the O 1s XPS spectra of ASC, ASC-10Mn, and ASC-10U10Mn, respectively. The O 1s spectra of all the samples could be fitted with 3 peaks, which were assigned to hydroxide groups $\left(\mathrm{O}_{\gamma}\right)$, surface chemical oxygen 
$\left(\mathrm{O}_{\alpha}\right)$, and crystal lattice oxygen $\left(\mathrm{O}_{\beta}\right)$. Loading manganese or nitrogen on catalysts did not affect the oxygen species, but did improve the $\mathrm{O}_{\alpha}$ and $\mathrm{O}_{\beta}$ concentrations, which promoted oxygen mobility and oxygen vacancies (Gao et al., 2018). The highest $\mathrm{O}_{\gamma}$ concentration was found on ASC and was beneficial for $\mathrm{NH}_{3}$ absorption as Brønsted sites, which was consistent with the $\mathrm{NH}_{3}$-TPD results. After loading manganese, the $\mathrm{O}_{\alpha}$ concentration increased from $35.7 \%$ of ASC to $64.4 \%$ of ASC-10Mn which exhibited the apparent improvement of de- $\mathrm{NO}_{x}$ activity. The literatures reported that $\mathrm{O}_{\alpha}$ could promote the oxidation of NO ( $\mathrm{Li}$ et al., 2017; Jiang et al., 2019), suggesting that the improved catalytic activity of ASC-10Mn could cause by the increased $\mathrm{O}_{\alpha}$. With the nitrogen doping, the $\mathrm{O}_{\alpha}$ concentration decreased, and the $\mathrm{O}_{\beta}$ and $\mathrm{O}_{\gamma}$ concentrations increased. The $\mathrm{O}_{\gamma}$ concentration of ASC-5U10Mn and ASC-10U10Mn was close (Fig. S4 and Table S2). There was the least $\mathrm{O}_{\alpha}$ and the most $\mathrm{O}_{\beta}$ on the most active ASC10U10Mn, but it exhibited the lowest O 1s binding energy among all catalysts, also indicating enhanced oxygen mobility (France et al., 2017). And the $\mathrm{O}_{\alpha}$ concentration is not the dominate factor to affect the low-temperature catalytic activity of ASC-10U10Mn.

\section{Table 3}

Distribution of sites from surface XPS: Concentration of oxygen species is determined from the $\mathrm{O} 1$ s peak and nitrogen species from the $\mathrm{N} 1 \mathrm{~s}$ peak. Number are given in $\%$.

\begin{tabular}{ccccccccccc}
\hline Sample & $\mathrm{O}^{a}$ & $\mathrm{O}_{\alpha}$ & $\mathrm{O}_{\beta}$ & $\mathrm{O}_{\gamma}$ & $\mathrm{N}^{a}$ & $\mathrm{~N}-6$ & $\mathrm{~N}-5$ & $\mathrm{~N}-\mathrm{Q}$ & $\mathrm{N}-\mathrm{X}$ & $-\mathrm{NO}_{2}$ \\
\hline ASC & 8.0 & 35.7 & 13.5 & 50.8 & 1.3 & 57.7 & - & - & 2.3 & 40.0 \\
ASC-10Mn & 8.2 & 64.4 & 17.1 & 18.5 & 1.2 & 91.4 & - & - & 4.8 & 3.8 \\
ASC-10U10Mn & 8.5 & 37.0 & 37.7 & 25.4 & 4.8 & 33.6 & 32.6 & 18.7 & - & 15.2 \\
\hline
\end{tabular}

${ }^{a}$ Oxygen and nitrogen content obtained from elemental analysis 

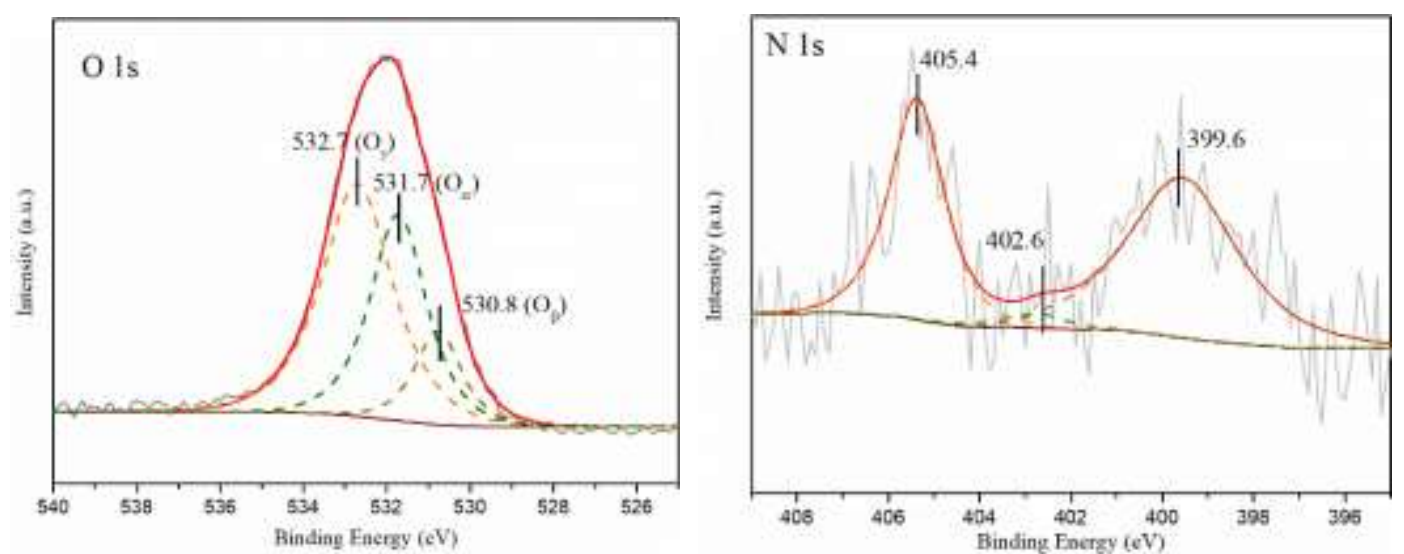

(a)
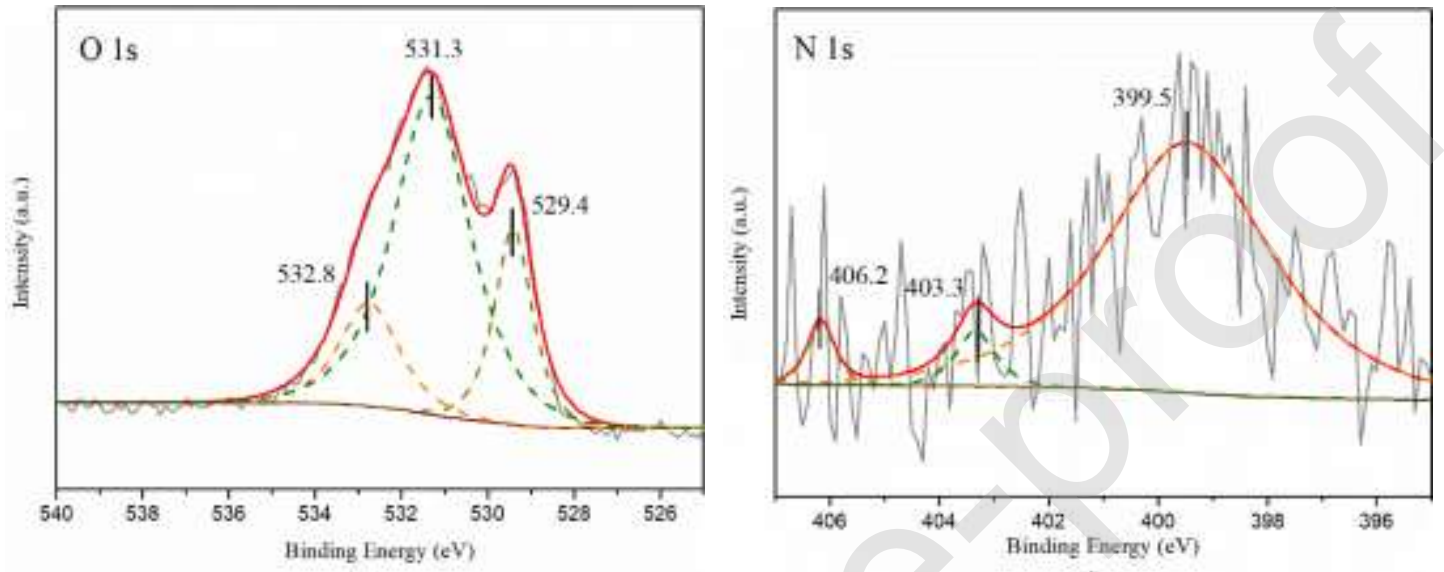

(c)

(d)

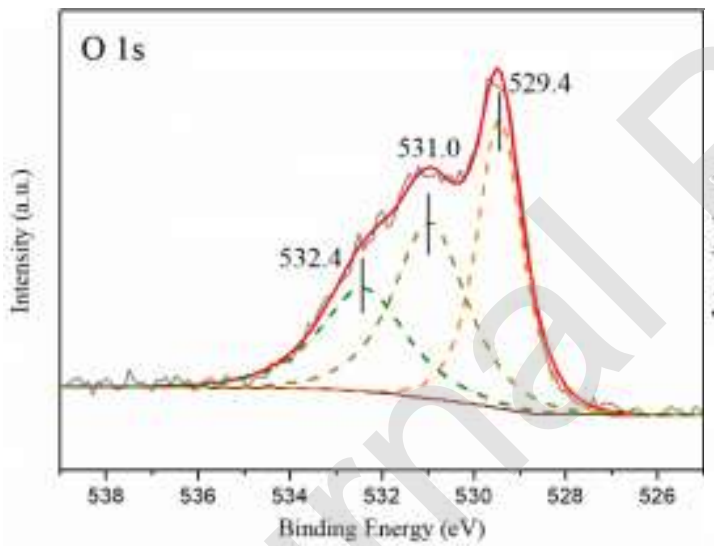

(e)

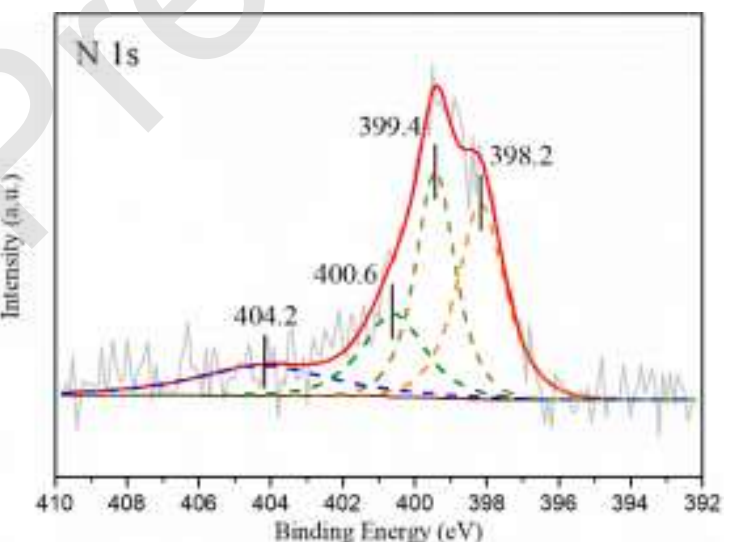

(f)

Fig.5 O 1s and N 1s XPS spectra of (a)(b) ASC, (c)(d) ASC-10Mn, (e)(f) ASC-10U10Mn

As shown in Figs. 5(b) and (d), the N 1s spectra of ASC and ASC-10Mn could be fitted with 3 peaks, assigned to pyridinic-N (N-6), oxidized pyridinic-N (N-X), and R-ONO (-NO $)$ (Yao et al., 2019). The N-6 concentration was $57.7 \%$ on ASC and increased to $91.4 \%$ on ASC-10Mn.

But the N-6 concentration gradually decreased and the new nitrogen species (quaternary-N, N- 
Q) was induced with N-doping, as shown in Fig.S4 and Table S2. For ASC-10U10Mn, the N6 concentration decreased sharply, and another new nitrogen species (pyrrolic-N, N-5) was induced (Yao et al., 2019; Shi et al., 2018). N-5 is mainly formed from the pyrolysis of any functional group containing $\mathrm{NH}_{2}$ (Strelko et al., 2000), consistent with the high dosage of urea during the modification. $\mathrm{N}-6, \mathrm{~N}-5$, and $\mathrm{N}-\mathrm{Q}$ all have similar structures where nitrogen is doped in the aromatic rings. N-5 and N-6 are both electron pair donors. For N-6, its lone pair is not part of the aromatic $\pi$-system and is available for donation. N-5 is a much weaker Lewis base than N-6 since its lone pair is engaged in the aromatic $\pi$-system. N-Q has $\mathrm{sp}^{2}$ hybridization and fully saturated bonding, which improves the electron mobility (Qiu et al., 2018). The electron distribution in catalysts was favorably affected by the addition of nitrogen functional groups.
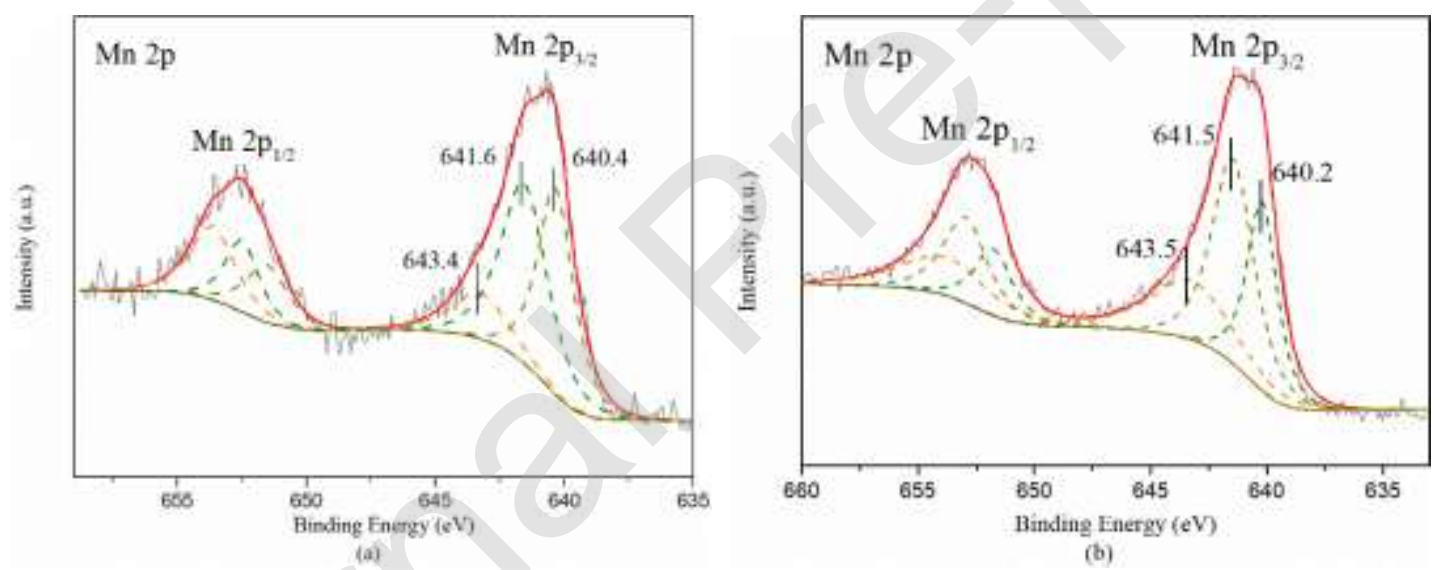

Fig.6 Mn 2p XPS spectra of (a) ASC-10Mn, (b)ASC-10U10Mn

Table 4

Distribution of sites from surface XPS: Concentration of manganese species from the Mn $2 p$ peak. Number are given in $\%$.

\begin{tabular}{ccccc}
\hline Sample & $\mathrm{Mn}^{b}$ & $\mathrm{Mn}^{2+}$ & $\mathrm{Mn}^{3+}$ & $\mathrm{Mn}^{4+}$ \\
\hline ASC-10Mn & 5.2 & 40.6 & 45.7 & 13.8 \\
ASC-10U10Mn & 5.3 & 30.1 & 44.8 & 25.1 \\
\hline
\end{tabular}




\section{${ }^{b}$ Manganese content obtained from ICP-OES}

The Mn 2p $\mathrm{p}_{3 / 2}$ spectra of all the catalysts could be fitted with 3 peaks (Fig. 6 and Fig. S4), corresponding to $\mathrm{Mn}^{2+}, \mathrm{Mn}^{3+}$, and $\mathrm{Mn}^{4+}$, consistent with the XRD results. The relative concentrations of the different Mn species were calculated and are listed in Table 4 and Table S2. $\mathrm{Mn}^{3+}$ was the dominant form of manganese on semi-coke catalysts. Jia et al. (Jia et al., 2016) reported that when $\mathrm{Mn}^{3+}$ is present in the framework of $\mathrm{MnO}_{2}$, oxygen vacancies can balance the charge as follows:

$$
4 M n^{4+}+O^{2-}(a d) \rightarrow 4 M n^{4+}+2 e^{-} / V_{O}+1 / 2 O_{2}(g) \rightarrow 2 M n^{4+}+2 M n^{3+}+V_{O}+1 / 2 O_{2}(\mathrm{~g})
$$

Where $V_{O}$ is the oxygen vacancy site. For ASC-10Mn, more oxygen vacancies were present, therefore there was the higher $\mathrm{O}_{\alpha}$ concentration (Table 3). Nevertheless, any peak assigned to $\mathrm{Mn}_{2} \mathrm{O}_{3}$ was not found in the corresponding XRD pattern, suggesting that $\mathrm{Mn}_{2} \mathrm{O}_{3}$ is the amorphous phase that is favorable for catalytic reduction (Zhang et al., 2016; Tang et al., 2007). Nitrogen doping has the least effect on the $\mathrm{Mn}^{3+}$ concentration and the more effect on the $\mathrm{Mn}^{2+}$ and $\mathrm{Mn}^{4+}$ concentrations. The $\mathrm{Mn}^{2+}$ and $\mathrm{Mn}^{3+}$ concentrations reduced and the $\mathrm{Mn}^{4+}$ concentration gradually increased with the $\mathrm{N}$-doping amount. There was only $30.1 \% \mathrm{Mn}^{2+}$ on ASC-10U10Mn, but the $\mathrm{Mn}^{4+}$ concentration was the highest: $\mathrm{Mn}^{4+} / \mathrm{Mn}^{3+}=0.56$. More active $\mathrm{Mn}^{4+}$ is beneficial to the oxidation of $\mathrm{NO}$ to $\mathrm{NO}_{2}$ and the promotion of catalytic activity. More specific analysis is stated in the following discussion.

\subsubsection{Redox performance}

$\mathrm{H}_{2}$-TPR was used for evaluating the reducibility of catalysts. The $\mathrm{H}_{2}-\mathrm{TPR}$ profiles are shown 
in Fig. 7. Gaussian fitting revealed that all the samples exhibited 4 overlapping reduction peaks. The 3 peaks in the range of $250-600^{\circ} \mathrm{C}$ derived from the 3 reduction steps: $\mathrm{MnO}_{2}$ to $\mathrm{Mn}_{2} \mathrm{O}_{3}$, $\mathrm{Mn}_{2} \mathrm{O}_{3}$ to $\mathrm{Mn}_{3} \mathrm{O}_{4}$, and $\mathrm{Mn}_{3} \mathrm{O}_{4}$ to $\mathrm{MnO}$. Another peak above $600^{\circ} \mathrm{C}$ was assigned to the reduction of oxygen functional groups on the surface of the matrix (Yan et al., 2017; Jiang et al., 2018).

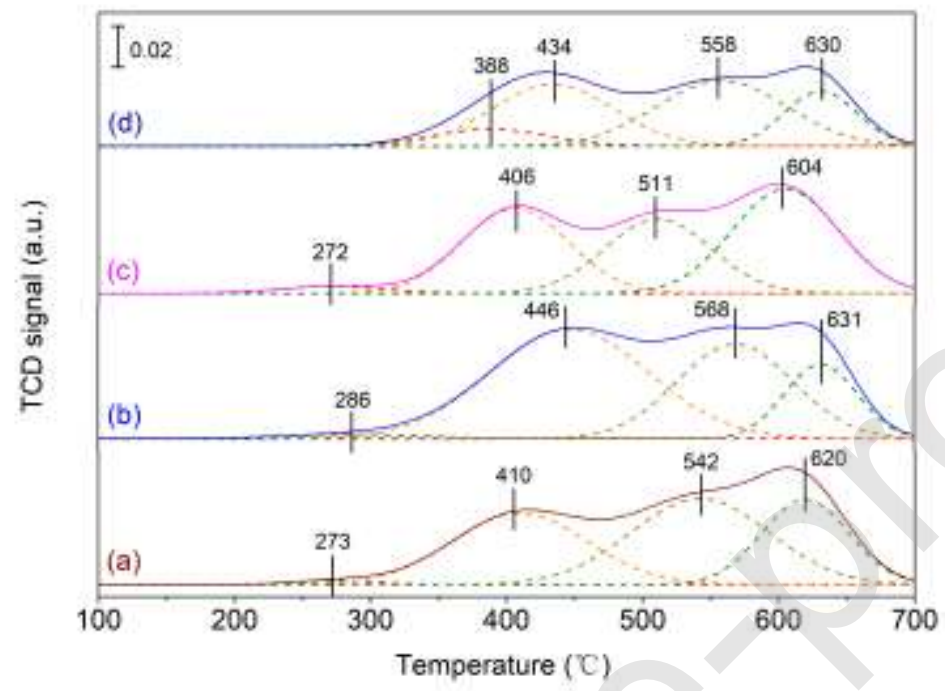

Fig. 7 The $\mathrm{H}_{2}$-TPR profiles of (a) ASC-10Mn, (b) ASC-10Mn-after, (c) ASC-10U10Mn, (d) ASC-10U10Mn-after

Compared with ASC-10Mn, all reduction peaks of nitrogen-doped $\mathrm{MnO}_{x} /$ semi-coke catalysts gradually shifted to lower temperatures, indicating that nitrogen-doped $\mathrm{MnO}_{x}$ /semi-coke catalysts were more reducible than ASC-10Mn. Combined with the XRD and XPS results, the amorphous phase $\mathrm{Mn}_{2} \mathrm{O}_{3}$ can remain on nitrogen-doped $\mathrm{MnO}_{x} /$ semi-coke catalysts, which might be one reason for the high reducibility. As shown in Table 5 and Table S3, the area ratio of the $\mathrm{MnO}_{2}$ to $\mathrm{Mn}_{2} \mathrm{O}_{3}$ reduction peak gradually increased with the N-doping amount, demonstrating more $\mathrm{Mn}^{4+}$ on ASC-10U10Mn. The largest $\mathrm{MnO}_{x}$ reduction peak of ASC10U10Mn was attributed to the reduction of $\mathrm{Mn}_{2} \mathrm{O}_{3}$ to $\mathrm{Mn}_{3} \mathrm{O}_{4}$, implying that $\mathrm{Mn}^{3+}$ is dominant. 
The area ratio of the same reduction peak over ASC-10Mn was a little larger than that of ASC10U10Mn, suggesting more $\mathrm{Mn}^{3+}$ over ASC-10Mn, in accordance with the XPS results. Furthermore, ASC-10U10Mn exhibited a larger reduction peak area for the oxygen functional groups on the semi-coke matrix, indicating that more oxygen functional groups were reduced. Nitrogen functional groups resulted in the increased reduction potential of oxygen species, making it possible to enhance the oxygen mobility of the catalysts. Accordingly, the reduction temperature of the oxygen species was reduced, implying that the oxygen species were easier to reduce, thus further promoting the redox property of ASC-10U10Mn.

\section{Table 5}

Relative area of reduction peaks of ASC10Mn and ASC10U10Mn before and after de-NO $x$ reaction determined from $\mathrm{H}_{2}$-TPR.

\begin{tabular}{ccccc}
\hline \multirow{2}{*}{ Sample } & \multicolumn{4}{c}{ Area ratio of reduction peak/\% } \\
\cline { 2 - 5 } & $\mathrm{MnO}_{2}$ to $\mathrm{Mn}_{2} \mathrm{O}_{3}$ & $\mathrm{Mn}_{2} \mathrm{O}_{3}$ to $\mathrm{Mn}_{3} \mathrm{O}_{4}$ & $\mathrm{Mn}_{3} \mathrm{O}_{4}$ to $\mathrm{MnO}$ & Semi-coke matrix \\
\hline ASC-10Mn & 1.1 & 33.0 & 40.6 & 25.2 \\
ASC-10Mn-after & 1.8 & 50.6 & 31.9 & 15.7 \\
ASC-10U10Mn & 2.7 & 31.6 & 27.5 & 38.3 \\
ASC-10U10Mn-after & 8.9 & 34.2 & 38.8 & 18.2 \\
\hline
\end{tabular}

All reduction peaks of the spent ASC-10Mn and ASC-10U10Mn shifted to higher temperature compared to the fresh catalysts, revealing that the reducibility of the active species had decreased. The area ratio of reduction peak of oxygen functional groups was reduced as well after reaction. This phenomenon indicates that oxygen functional groups are simultaneously involved in the SCR reaction. 


\subsubsection{Acidic performance}

$\mathrm{NH}_{3}$-TPD was used to estimate the surface acidity of catalysts. Fig. 8(a) and Fig. S6 show the $\mathrm{NH}_{3}$-TPD patterns of the ASC, ASC-10Mn, ASC-5U10Mn, and ASC-10U10Mn catalysts. The surface acidity was calculated and is listed in Table 6 and Table S4. The TPD patterns of all the samples displayed a desorption peak around $114^{\circ} \mathrm{C}$, which derived from the breakage of fairly weak hydrogen bonds between adsorbed $\mathrm{NH}_{3}$ and surface acidic groups (Wang et al., 2015). ASC exhibited distinctive Brønsted acid and Lewis acid sites at $382^{\circ} \mathrm{C}$ and $605^{\circ} \mathrm{C}$, respectively (You et al., 2017). For ASC-10Mn, the desorption peak assigned to the Brønsted acid sites shifted to a higher temperature, whereas the peak assigned to the Lewis acid sites remained unchanged, revealing that the addition of $\mathrm{MnO}_{x}$ led to the enhanced strength of the Brønsted acid sites. The decreased areas of all desorption peaks implied that ASC-10Mn could possess relatively few Brønsted acid and Lewis acid sites. The addition of $\mathrm{MnO}_{x}$ made it possible for some manganese to be present at the ion exchange sites, thereby reducing acid sites, something that was also observed in other catalysts (Sultana et al., 2012). The Brønsted and Lewis acid sites on catalysts were affected significantly by nitrogen doping. With the N-doping amount, the desorption peak attributed to the Brønsted acid sites gradually disappeared, and the strong peak attributed to the Lewis acid sites around $555^{\circ} \mathrm{C}$ gradually increased. 

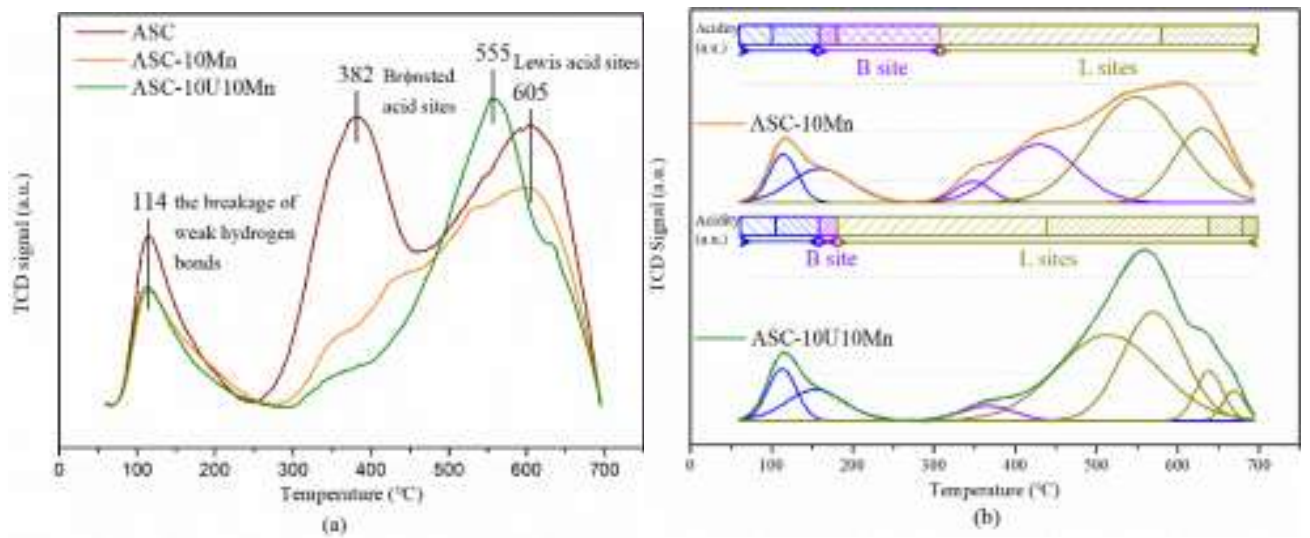

Fig. $8 \mathrm{NH}_{3}$-TPD profiles of semi-coke catalysts

\section{Table 6}

Surface acidity of semi-coke catalysts determined by $\mathrm{NH}_{3}-\mathrm{TPD}$

\begin{tabular}{ccc}
\hline \multirow{2}{*}{ Sample } & \multicolumn{2}{c}{ Surface acidity $/ \mathrm{mmol} \cdot \mathrm{g}^{-1}$} \\
\cline { 2 - 3 } & Brønsted acid sites & Lewis acid sites \\
\hline ASC & 0.24 & 0.36 \\
ASC-10Mn & 0.10 & 0.27 \\
ASC-10U10Mn & 0.02 & 0.35 \\
\hline
\end{tabular}

Gaussian fitting was employed to further explore the acid site changes, as shown in Fig. 8(b).

The desorption peaks related to the Brønsted acid site in the range $250-440^{\circ} \mathrm{C}$ and the Lewis acid site above $450^{\circ} \mathrm{C}$ were broader for ASC-10Mn compared to ASC. These peaks required fitting with 2 Gaussian functions each, indicating the presence of multiple Brønsted and Lewis acid sites of different strengths. The desorption peaks of ASC-10U10Mn were fitted to only 1 Brønsted acid site and 4 different Lewis acid sites. After nitrogen doping, fewer Brønsted acid sites were present, but a greater diversity of species and more Lewis acid sites were present on ASC-10U10Mn. This is possibly a result of the retaining dispersion of active phases and the increased number of active sites after nitrogen doping. 


\subsubsection{In situ DRIFTS characterization}

In situ DRIFTS was used to investigate the intermediates, the reaction pathway, and the possible reaction mechanisms of nitrogen-doped $\mathrm{MnO}_{x} /$ semi-coke catalysts at low temperatures. The formation of active sites, the transformation of adsorbed species, and the generation of intermediates over the ASC-10U10Mn catalyst were compared and analyzed based on the successive in situ DRIFT spectra recorded during different gas conditions. As illustrated in Fig. 9, in situ DRIFT spectra of ASC-10U10Mn were recorded at $200^{\circ} \mathrm{C}$ while exposed in sequence to $\mathrm{NH}_{3}, \mathrm{NO}+\mathrm{O}_{2}$, and $\mathrm{SCR}$ atmospheres for $30 \mathrm{~min}$.

Adsorption of $\mathbf{N H}_{3}$. When ASC-10U10Mn was exposed to an $\mathrm{NH}_{3}$ atmosphere, as shown in Fig. 9(a), clear changes were observed in the bands at 768, 930, 965, 1085, 1540, 1552, 1649, and $1685 \mathrm{~cm}^{-1}$. The band at $768 \mathrm{~cm}^{-1}$ appearing in all the spectra was assigned to Si-O. It has been ascertained by $\mathrm{XRD}$ that $\mathrm{SiO}_{2}$ is always present on semi-coke catalysts (Lu et al., 2018). The noticeable bands at 930 and $965 \mathrm{~cm}^{-1}$ appeared whenever the catalyst was exposed to $\mathrm{NH}_{3}$. They were assigned to either gas phase or weakly adsorbed $\mathrm{NH}_{3}$. The band at $930 \mathrm{~cm}^{-1}$ exhibited slower change and lower intensity than the band at $965 \mathrm{~cm}^{-1}$, although it gradually stabilized with time. The band at $1085 \mathrm{~cm}^{-1}$ and the weak bands at $1624 \mathrm{~cm}^{-1}$ represented the symmetric and asymmetric $\mathrm{N}-\mathrm{H}$ bending vibrations of coordinated $\mathrm{NH}_{3}$ on Lewis acid sites, respectively (Yan et al., 2017; Gao et al., 2017; Yu et al., 2017; Chen et al., 2015). The bands at 1649 and $1685 \mathrm{~cm}^{-1}$ were attributed to the symmetric bending vibrations of $\mathrm{NH}_{4}{ }^{+}$species after reaction with Brønsted acid sites (Yu et al., 2017; Wang et al., 2014b). The changes of the weak bands at 1540 and $1552 \mathrm{~cm}^{-1}$ were attributed to amide species $\left(-\mathrm{NH}_{2}\right)$ and intermediates from the partial oxidation of $\mathrm{NH}_{3}$ (Yan et al., 2017; Chen et al., 2015). As explained in the literature (Yu 
et al., 2017), $-\mathrm{NH}_{2}$ species may arise from the partial oxidation of $\mathrm{NH}_{3}$ caused by the abundant $\mathrm{Mn}^{3+}$ species on ASC-10U10Mn. The bands in the range of $1495-1510 \mathrm{~cm}^{-1}$ and $1560-1575$ $\mathrm{cm}^{-1}$ due to pyridinic and pyrrolic structure, respectively, appeared and remained stable with time (Jia et al., 2002).

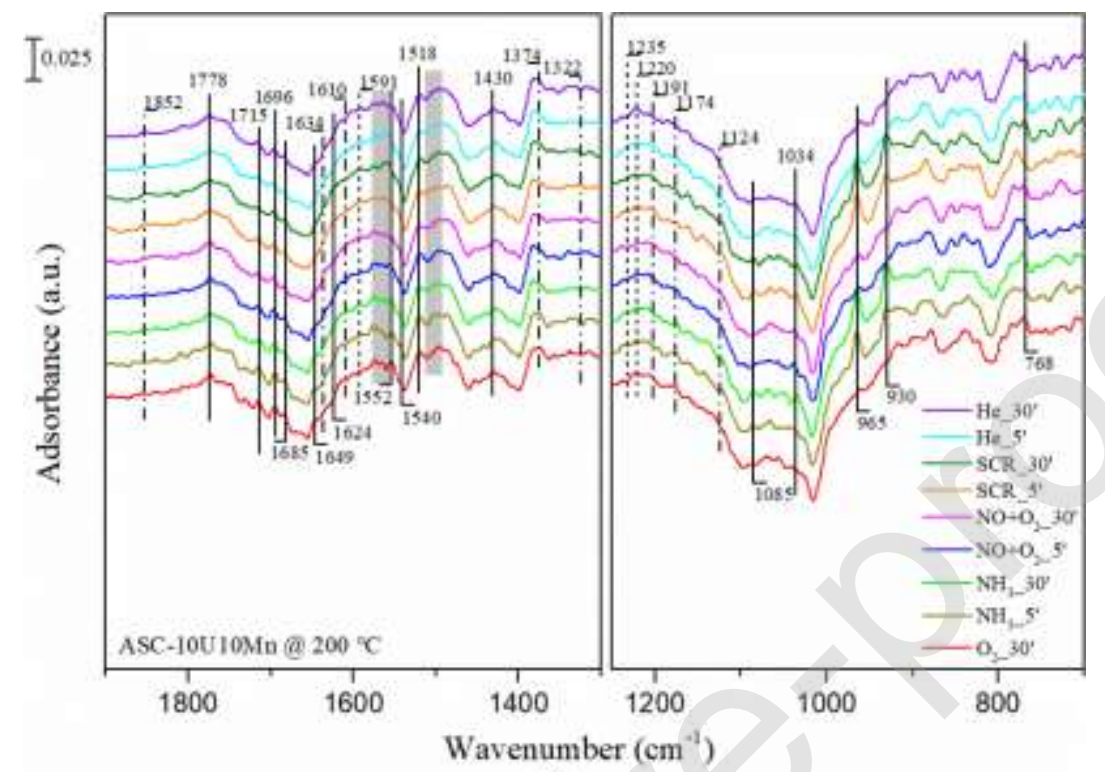

(a)
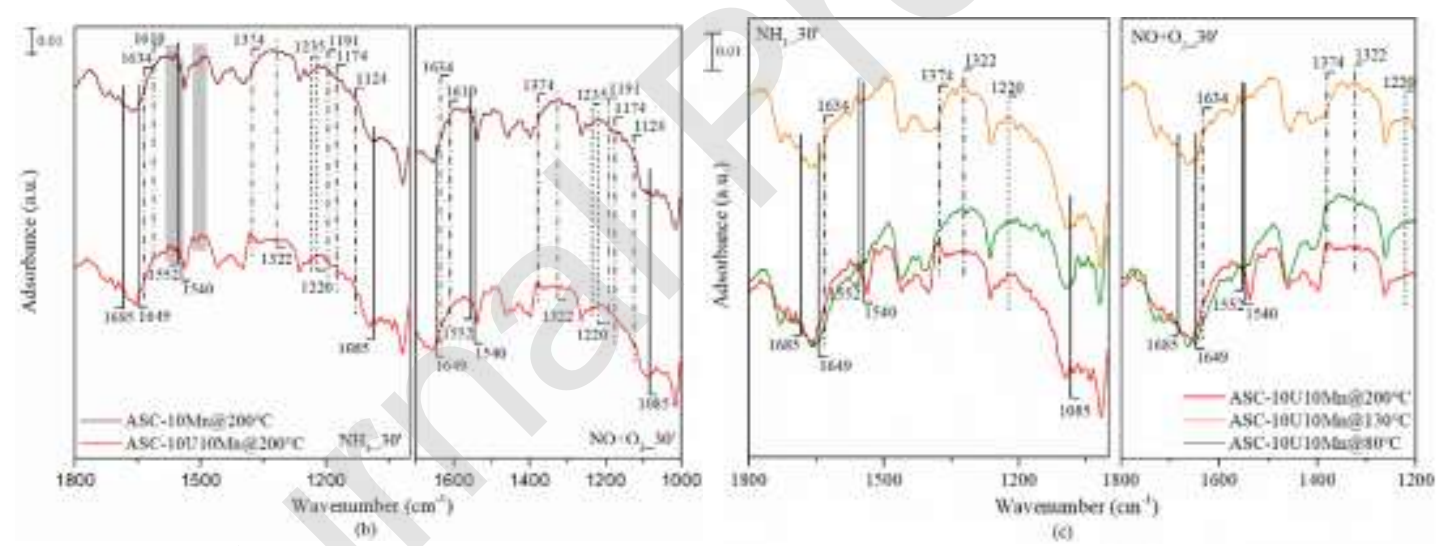

Fig. 9 in situ DRIFT spectra of semi-coke catalysts exposed to different atmospheres (a)

Selected spectra of ASC-10U10Mn at $200^{\circ} \mathrm{C}$ during a single experiment where the sample is sequentially exposed to different gas mixtures, (b) Comparison of ASC-10Mn and ASC$10 \mathrm{U} 10 \mathrm{Mn}$ at $200^{\circ} \mathrm{C}$ in $\mathrm{NH}_{3}$ and in $\mathrm{NO}+\mathrm{O}_{2}$, (c) Comparison of the same sample and gas mixtures as in b) at different temperatures. 
Co-adsorption of $\mathrm{NO}$ and $\mathrm{O}_{2}$. When a mixture of $\mathrm{NO}$ and $\mathrm{O}_{2}$ was introduced into the reaction chamber, the weak bands at 1124 and $1852 \mathrm{~cm}^{-1}$ ascribed to either gas phase or weakly adsorbed $\mathrm{NO}$ appeared, and the gas phase or weakly adsorbed $\mathrm{NH}_{3}$ associated with the bands at 965 and $930 \mathrm{~cm}^{-1}$ disappeared immediately. As the chamber with the sample was being purged for $30 \mathrm{~min}$, a new band at $1634 \mathrm{~cm}^{-1}$ assigned to either gas phase or weakly adsorbed $\mathrm{NO}_{2}$ appeared (Chen et al., 2015; Wang et al., 2014b). As time increased, the band at $1174 \mathrm{~cm}^{-}$ ${ }^{1}$ assigned to cis- $\mathrm{N}_{2} \mathrm{O}_{2}{ }^{2-}$ was observed (Yan et al., 2017; Chen et al., 2015), suggesting the improved oxidation of $\mathrm{NO}$ to $\mathrm{NO}_{2}$. A band at $1191 \mathrm{~cm}^{-1}$ assigned to anionic nitrosyl $\mathrm{NO}^{-}$species was also detected (Gao et al., 2018; Qi et al., 2004). This species was expected to be oxidized to nitrate or nitrite in the presence of oxygen. Bridging nitrate at $1610 \mathrm{~cm}^{-1}$, as well as the band at $1322 \mathrm{~cm}^{-1}$ assigned to bidentate nitrate (Yu et al., 2017), appeared immediately after passing the $\mathrm{NO}+\mathrm{O}_{2}$ gas mixture for $5 \mathrm{~min}$. The band at $1374 \mathrm{~cm}^{-1}$ assigned to the free nitrate ion $\left(-\mathrm{NO}_{3}{ }^{-}\right)$ (Hadjiivanov et al., 2000) decreased upon exposure to $\mathrm{NH}_{3}$, implying that free nitrate ions could adsorb $\mathrm{NH}_{3}$ and possibly generate intermediates. When the gas turned to $\mathrm{NO}$ and $\mathrm{O}_{2}$, the band at $1374 \mathrm{~cm}^{-1}$ appeared again. Notably, the intensity of the bands assigned to the pyridinic and pyrrolic groups decreased over the 30 min exposure to $\mathrm{NO}$ and $\mathrm{O}_{2}$. It can be speculated that $\mathrm{N}$ doping contributed to the adsorption of NO and the further oxidation of NO. The intensity of the bands of any coordinated $\mathrm{NH}_{3}$ and $\mathrm{NH}_{4}{ }^{+}$decreased at different degrees, implying that both coordinated $\mathrm{NH}_{3}$ and $\mathrm{NH}_{4}{ }^{+}$species participate in the $\mathrm{SCR}$ reaction.

The spectra of ASC-10Mn and ASC-10U10Mn under the same atmosphere were compared in Fig. 9(b). In the case of $\mathrm{NH}_{3}$, the bands at 1540, 1552, 1649, and $1685 \mathrm{~cm}^{-1}$ could be observed clearly over ASC-10U10Mn, while those same bands were barely visible in the spectra of ASC- 
10Mn. The band at $1085 \mathrm{~cm}^{-1}$ assigned to coordinated $\mathrm{NH}_{3}$ on Lewis acid sites was present in the spectra of both catalysts, but the intensity for ASC-10U10Mn was much higher than ASC$10 \mathrm{Mn}$. After passing the gas mixture of $\mathrm{NO}$ and $\mathrm{O}_{2}$, this band disappeared immediately over ASC-10U10Mn, but remained over ASC-10Mn with weak intensity, suggesting less coordinated $\mathrm{NH}_{3}$ available to participate in the LT SCR reaction. Nitrogen doping not only provided more active sites to adsorb ammonia species, but also promoted coordinated $\mathrm{NH}_{3}$ for the SCR reaction.

The spectra of ASC-10U10Mn were compared at different temperatures, as shown in Fig. 9(c). When the catalyst was exposed to $\mathrm{NH}_{3}$ at lower temperatures, the intensity of the bands at $1085,1540,1552$, and $1649 \mathrm{~cm}^{-1}$ vanished to varying degrees. In particular, the band at 1540 $\mathrm{cm}^{-1}$ assigned to amide species changed significantly. Amide species are possibly more active than other adsorbed ammonia species at low temperatures. The bands at 1374 and $1634 \mathrm{~cm}^{-1}$ assigned to free nitrate ions and either gas phase or weakly adsorbed $\mathrm{NO}_{2}$ were also affected by temperature as the gas mixture of $\mathrm{NO}$ and $\mathrm{O}_{2}$ was purged in the reaction chamber.

SCR steady-state reaction. The formation of surface species on the ASC-10U10Mn in an SCR atmosphere was also examined. Besides the bands at 965 and $930 \mathrm{~cm}^{-1}$, coordinated $\mathrm{NH}_{3}$ and $\mathrm{NH}_{4}^{+}$species were again detected at 1085,1624 , and $1685 \mathrm{~cm}^{-1}$. The band at $1174 \mathrm{~cm}^{-1}$ assigned to cis- $\mathrm{N}_{2} \mathrm{O}_{2}{ }^{2-}$ was observed in steady state conditions. In addition, the presence of bidentate nitrate and bridging nitrite was suggested due to the observation of bands at 1220 and $1235 \mathrm{~cm}^{-1}$, respectively (Yu et al., 2017). Bridging nitrates at $1610 \mathrm{~cm}^{-1}$ were consumed as monodentate nitrates appeared at $1591 \mathrm{~cm}^{-1}$. Certainly, $\mathrm{H}_{2} \mathrm{O}$ with a strong band in the range $3420-3750 \mathrm{~cm}^{-1}$ also appeared, and the intensity of this band continued to increase, indicating 
that the SCR reaction had taken place. Bridging nitrate at 1235 and $1610 \mathrm{~cm}^{-1}$ was consumed in the first 5 min after ammonia was introduced, and then gradually accumulated until reaching a steady state. Considering the changes of bands at 1540 and $1552 \mathrm{~cm}^{-1}$ in above single experiments, $-\mathrm{NH}_{2}$ participated in the LT SCR reaction continuously and played an important role based on the significant decrease in intensity of bands assigned to intermediates $-\mathrm{NH}_{2}$ at the SCR steady-state experiment. In addition, the bands assigned to $\mathrm{C}=\mathrm{O}$ vibrations and $\mathrm{C}=\mathrm{C}$ bonds in an aromatic ring could also be observed at 1778(1430) and $1715 \mathrm{~cm}^{-1}$, but the changes of the atmosphere barely have effects on these bands.

\subsection{Mechanism discussion}

It is common knowledge that the morphology and structural features of catalysts are directly related to catalytic performance. Based on the preceding analysis, nitrogen doping indeed optimized the morphology of ASC-10U10Mn. However, ASC-10U10Mn with surface area of $38.0 \mathrm{~m}^{2} / \mathrm{g}$ and total pore volume of $0.026 \mathrm{~cm}^{3} / \mathrm{g}$ has the superior catalytic performance compared with other samples. It is not consistent with the typical expectation that developed pores promote the activity of a catalyst by providing larger surface area and pore volume ( $\mathrm{Lu}$ et al., 2018). This implies that in addition to the morphology and structure, internal chemical properties also play a vital role in promoting catalytic performance in the LT SCR reaction. Based on the above DRIFTS results, it can be confirmed that $\mathrm{NH}_{3}$ species were adsorbed over ASC-10U10Mn by different paths, as described by Equations (1)-(4). Gaseous $\mathrm{NH}_{3}$ is initially adsorbed on Lewis acid sites to form coordinated $\mathrm{NH}_{3}$, and also on Brønsted acid sites, leading to the appearance of $\mathrm{NH}_{4}{ }^{+}$. The literature (Yu et al., 2017; Chen et al., 2015) suggests that 
adsorbed $\mathrm{NH}_{3}$ on Lewis acid sites plays an important role in the SCR reaction. For ASC$10 \mathrm{U} 10 \mathrm{Mn}$, this is reflected in the obvious changes of the stable bands at 1085 and $1624 \mathrm{~cm}^{-1}$ assigned to coordinated $\mathrm{NH}_{3}$ in Fig. 9(a), indicating that coordinated $\mathrm{NH}_{3}$ on Lewis acid sites is more active than $\mathrm{NH}_{4}{ }^{+}$on Brønsted acid sites. Besides, nitrogen doping provided the abundant nitrogen functional groups and improved $\mathrm{O}_{\beta}$ concentration on ASC-10U10Mn. The mobility of electrons between manganese in different valences could improve via the presented oxygen bridge of Mn-O-Mn on ASC-10U10Mn, which would promote the generation of oxygen vacancy. It could be one reason that nitrogen doping promoted the SCR performance of ASC-10U10Mn. Hence, coordinated $\mathrm{NH}_{3}$ could be oxidized to form the new amide species $\left(-\mathrm{NH}_{2}\right)$ intermediates.

$$
\begin{gathered}
\mathrm{NH}_{3}(\mathrm{~g}) \stackrel{\text { Lewis acid sites }}{\longrightarrow} \mathrm{NH}_{3}(\text { ads }) \\
\mathrm{NH}_{3}(\mathrm{~g})+\mathrm{H}^{+}(\text {Brønsted acid sites }) \rightarrow \mathrm{NH}_{4}^{+}(\text {ads }) \\
\mathrm{O}_{2}(\mathrm{~g}) \rightarrow 2 \mathrm{O}(\text { ads }) \\
\mathrm{NH}_{3}(\text { ads })+\mathrm{O}(\text { ads }) / \mathrm{O}^{2-}(\text { ads }) \stackrel{\mathrm{Mn}^{3+}}{\longrightarrow}-\mathrm{NH}_{2}(\text { ads })+\mathrm{OH}(\text { ads })
\end{gathered}
$$

A previous study (Ramis et al., 1990) has proposed that the formation of $-\mathrm{NH}_{2}$ is a vital step in the LT SCR reaction. As shown in the IR spectra, the intensity of the bands assigned to $-\mathrm{NH}_{2}$ rapidly decreased upon introduction of $\mathrm{NO}$ and $\mathrm{O}_{2}$ into the reaction chamber. The $-\mathrm{NH}_{2}$ species exhibited weak peaks in the SCR steady-state reaction, and we suggest that $-\mathrm{NH}_{2}$ species are actively contributing to the LT SCR reaction. Gas phase or weakly adsorbed $\mathrm{NH}_{3}$ is continually transferred to coordinated $\mathrm{NH}_{3}$ and $\mathrm{NH}_{4}{ }^{+}$, which is consistent with the dramatic decrease in intensity of the bands at 965 and $930 \mathrm{~cm}^{-1}$. In this study, the intensity of the bands assigned to $\mathrm{NH}_{4}{ }^{+}$decreased slightly, implying that $\mathrm{NH}_{4}{ }^{+}$reactivity was relatively low. By comprehensively 
considering the changes of adsorbed $\mathrm{NH}_{3}$ species, it can be concluded that coordinated $\mathrm{NH}_{3}$ and $-\mathrm{NH}_{2}$ species play an important role in the SCR reaction.

$$
\begin{aligned}
& -\mathrm{NH}_{2}(\text { ads })+\mathrm{NO}(\mathrm{g}) \rightarrow \mathrm{NH}_{2} \mathrm{NO}(\text { ads }) \rightarrow \mathrm{N}_{2}(\mathrm{~g})+\mathrm{H}_{2} \mathrm{O}(\mathrm{g}) \\
& \mathrm{NH}_{4}^{+}(\text {ads }) \rightarrow-\mathrm{NH}_{2}(\text { ads })+2 \mathrm{H}^{+}(\text {Brønsted acid sites })+e^{-}
\end{aligned}
$$

In general, NO can be adsorbed over ASC-10U10Mn due to the intrinsic $\pi$-bonds and functional groups. XPS characterization reveals a greater abundance of pyridinic-N, pyrrolic$\mathrm{N}$, and quaternary-N as active sites over ASC-10U10Mn. The unpaired electrons in $\mathrm{N}-6$ and $\mathrm{N}-$ 5 acting as "Lewis bases" are available for interaction with empty $\pi$-antibonding orbitals in the NO molecule (Wang et al., 2018; Qiu et al., 2018), which can promote NO adsorption. The adsorbed $\mathrm{NO}$ can then be further oxidized to $\mathrm{NO}_{2}$, cis- $\mathrm{N}_{2} \mathrm{O}_{2}{ }^{2-}$, and $-\mathrm{NO}_{3}{ }^{-}$to maintain the turnover of redox reactions in the SCR process. The oxidation of NO develops via the L-H mechanism and is the limiting step for the SCR reaction. Combined with the XPS results, it can be surmised that the increased NO conversion of ASC-10U10Mn is closely related to the enhanced oxidation of NO.

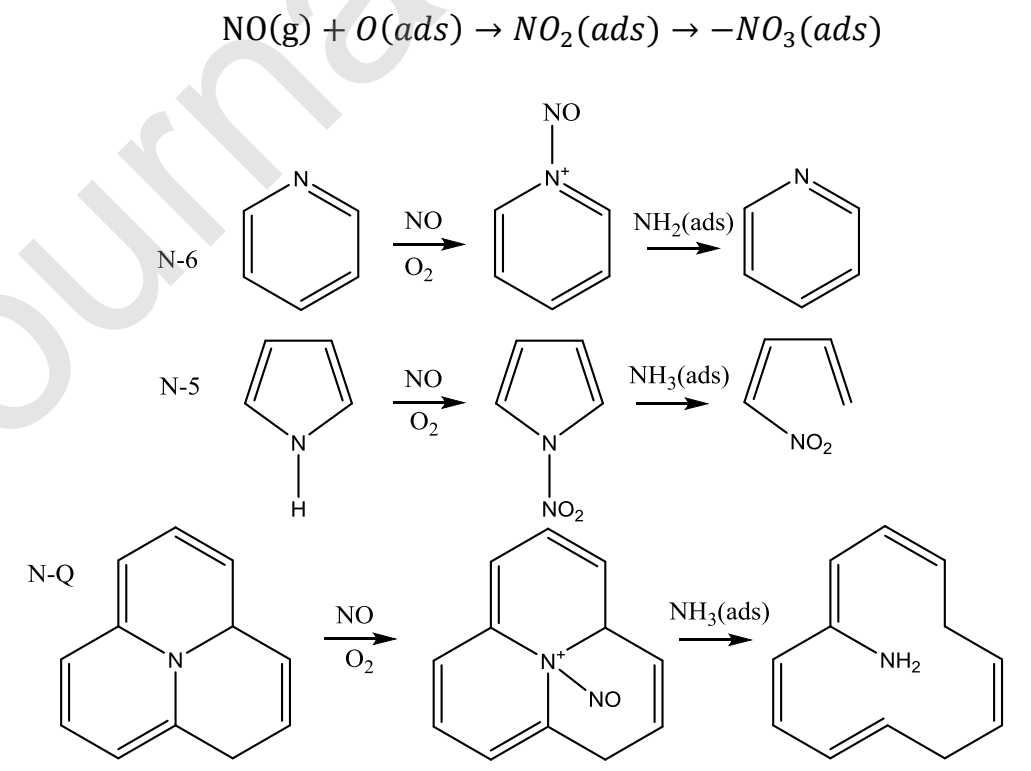

The intermediates derived from the NO adsorption of these nitrogen functional groups can be 
further reduced by coordinated $\mathrm{NH}_{3}$ or $-\mathrm{NH}_{2}$ species; accordingly, the intensity of the bands assigned to the pyridinic and pyrrolic decreased gradually, as reflected in the IR spectra. In addition to the fact that gaseous or weakly adsorbed $\mathrm{NO}$ and $\mathrm{NO}_{2}$ can be detected successively, some nitrate species were generated and kept stable $\left(1610,1591,1322,1235\right.$, and $1220 \mathrm{~cm}^{-1}$ in Fig. 9(a)). The generated nitrate species on the catalyst could be described as follow:
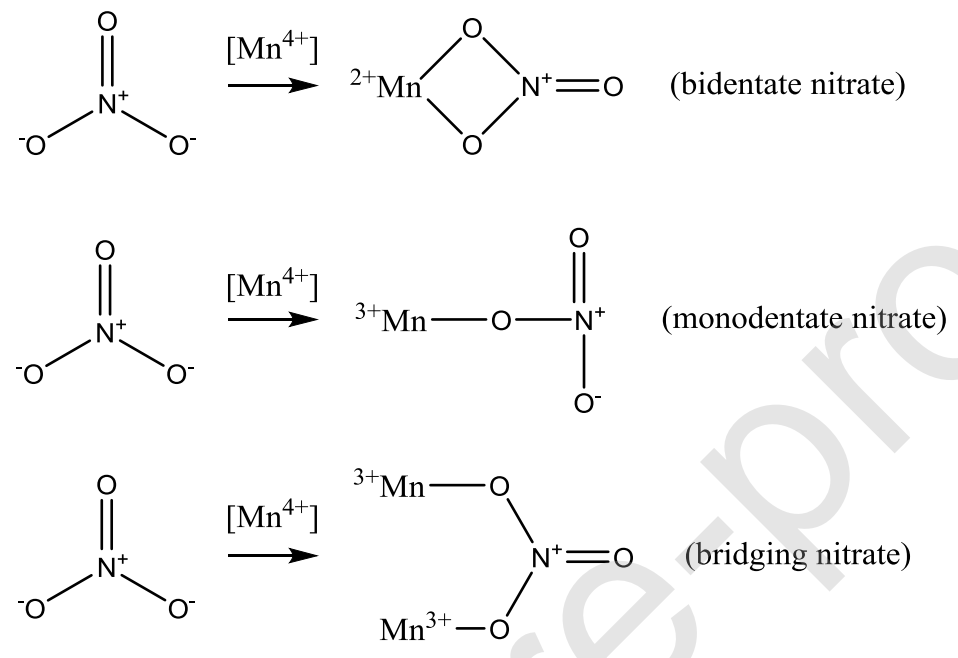

$\left[\mathrm{Mn}^{3+}\right]-\mathrm{ONO}_{2}$ (monodentate nitrate) $\leftrightarrow\left[\mathrm{Mn}^{2+}\right]=\mathrm{O}_{2} \mathrm{NO}$ (bidentate nitrate)

$$
\begin{array}{r}
\left.\left[\mathrm{Mn}^{3+}\right]-\mathrm{ONO}_{2} \text { (monodentate nitrate }\right)+\left[\mathrm{Mn}^{3+}\right]+\mathrm{V}_{\mathrm{O}} \leftrightarrow \\
{\left[2 \mathrm{Mn}^{3+}\right]=\mathrm{ONO}_{2} \text { (bridging nitrate) }}
\end{array}
$$

As shown in Fig. 9(a), bridging nitrate apparently existed over ASC-10U10Mn in 5min as passing $\mathrm{NO}$ and $\mathrm{O}_{2}$; bidentate nitrate then formed and was stable for $30 \mathrm{~min}$. Yu et al. (Yu et al., 2017) reported that bidentate nitrate can occupy active sites but cannot react with $\mathrm{NH}_{3}$, which agrees with the increasing accumulation of the bands assigned to bidentate nitrate and the subsequent formation of monodentate nitrate when the SCR gas passed through the catalyst. Although bidentate nitrate is inactive in the LT SCR reaction, it can be affected by $\mathrm{NH}_{3}$. Qi et al. and Peña et al. (Qi et al., 2004; Peña et al. 2004) explained that a similar phenomenon is possibly caused by electron transfer between $\mathrm{NH}_{3}$ and nitro species. Therefore, it is reasonable to deduce that the role of pyrrolic-N and quaternary-N over ASC-10U10Mn should not be 
neglected in the LT SCR reaction. Additionally, as an essential intermediate, bridging nitrate promotes the evolution of the LT SCR process; the reaction scheme can be described as Equation (12) and (13), which is consistent with previous studies (Chen et al., 2015). Based on the comparison in Fig. 9(b), there are more adsorbed $\mathrm{NH}_{3}$ species and nitrate species on ASC-10U10Mn than on ASC-10Mn. $\mathrm{NH}_{3}$-TPD analysis also proved the existence of abundant Lewis acid sites on the catalyst from nitrogen doping, which plays an important role in the enhancement of $\mathrm{NH}_{3}$ adsorption and is related to the LT SCR activity. This demonstrates that ASC-10U10Mn contains more active sites than ASC-10Mn, since nitrogen doping supplies an abundance of nitrogen functional groups and promotes electron transfer. Accordingly, LT SCR performance is significantly promoted by nitrogen doping. The promotional mechanism of nitrogen doping on $\mathrm{MnO}_{x} /$ semi-coke catalyst can be summarized as Fig. 10.

$$
\begin{gathered}
\mathrm{NH}_{2}(\text { ads })+-\mathrm{ONO}_{2}(\text { monodentate nitrate }) /=\mathrm{ONO}_{2} \text { (bridging nitrate) } \\
/=\mathrm{O}_{2} \mathrm{NO}(\text { bidentate nitrate }) \rightarrow \cdots \rightarrow \mathrm{N}_{2}(\mathrm{~g})+\mathrm{H}_{2} \mathrm{O}(\mathrm{g}) \\
\left.\mathrm{NH}_{3}(\text { ads }) / \mathrm{NH}_{2}(\text { ads }) / \mathrm{NH}_{4}^{+}(\text {ads })+=\mathrm{ONO}_{2} \text { (bridging nitrate }\right) \rightarrow \cdots \rightarrow \mathrm{N}_{2}(\mathrm{~g})+\mathrm{H}_{2} \mathrm{O}(\mathrm{g})
\end{gathered}
$$

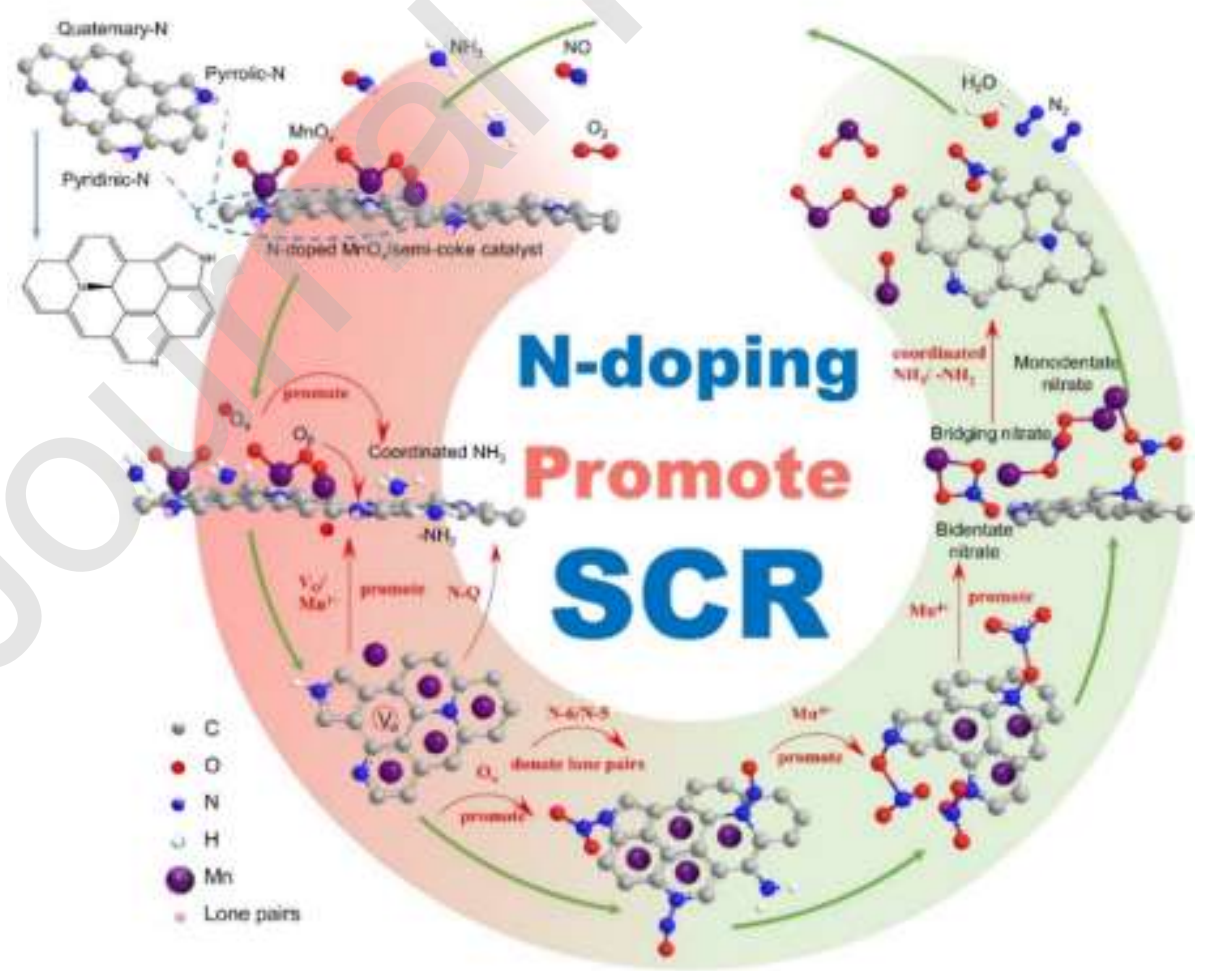


Fig.10 Promotional mechanism of nitrogen doping on $\mathrm{MnO}_{x} /$ semi-coke catalyst for LT SCR

\section{Conclusion}

In summary, nitrogen doping on $\mathrm{MnO}_{x} /$ semi-coke catalysts results in markedly improved $\mathrm{NH}_{3}$-SCR catalytic performance at low temperatures. The NO conversion of the ASC$10 \mathrm{U} 10 \mathrm{Mn}$ catalyst was $>50 \%$ at $125^{\circ} \mathrm{C}$ and higher, and exhibited the optimum of $94.5 \%$ at $275^{\circ} \mathrm{C}$. Besides the morphology and structure, nitrogen doping can promote the SCR reactivity of the catalyst by influencing the internal chemical properties. The formation of nitrogen functional groups led to the enhanced electron mobility and further promoted the oxidation of coordinated $\mathrm{NH}_{3}$. The generation of intermediate $-\mathrm{NH}_{2}$ species is critical in the LT SCR reaction. And the presence of pyridinic- $\mathrm{N}$ and pyrrolic- $\mathrm{N}$ is especially beneficial to adsorb NO and contributes to the transformation of inactive bidentate nitrate species. The formation of bridging nitrates could also accelerate the reaction with adsorbed $\mathrm{NH}_{3}$ species and be favorable for further $\mathrm{LT} \mathrm{NH}_{3}-\mathrm{SCR}$ reaction.

CRediT author statement

Lu Yao: Conceptualization, Methodology, Writing-Original draft preparation, Investigation, Formal analysis

Qingcai Liu: Supervision, Methodology, Resources, Funding acquisition

Susanne Mossin: Methodology, Resources, Writing-Review \& Editing

David Nielsen: Investigation, Visualization

Ming Kong: Validation, Writing-Review \& Editing

Lijun Jiang: Investigation, Formal analysis, Validation,

Jie Yang: Investigation, Formal analysis, Writing-Review \& Editing

Shan Ren: Conceptualization, Funding acquisition, Project administration

Juan Wen: Resources, Investigation, Writing-Review \& Editing 


\section{Declaration of interests}

The authors declare that they have no known competing financial interests or personal relationships that could have appeared to influence the work reported in this paper.

The authors declare the following financial interests/personal relationships which may be considered as potential competing interests:

\section{Acknowledgments}

The authors gratefully acknowledge the financial support from the National Natural Science Foundation of China (Nos. 51874058 and 51604048); the Fund of Chongqing Science and Technology (Nos. cstc2017shms-zdyfx0055 and cstc2016zdcy-ztzx20001) Chongqing Key Technology Innovation of Industries (No. cstc2016zdcy-ztzx20006); the program of Cheng Tou Road and Bridge Administration Co. Ltd.

\section{References}

Chen, Y., Wang, J., Yan, Z., Liu, L., Zhang, Z., Wang, X., 2015. Promoting effect of Nd on the reduction of $\mathrm{NO}$ with $\mathrm{NH}_{3}$ over $\mathrm{CeO}_{2}$ supported by activated semi-coke: an in situ DRIFTS study. Catal. Sci. Technol. 5, 2251-2259.

Chuang, K., Lu, C., Wey, M.Y., Huang, Y., 2011. NO removal by activated carbon-supported copper catalysts prepared by impregnation, polyol, and microwave heated polyol processes. Appl. Catal. A-General 397, 234-240. 
Fan, C., Xiang, J., Su, S., Wang, P., Sun, L., Hu, S., 2014. The activity and characterization of $\mathrm{MnO}_{x}-\mathrm{CeO}_{2}-\mathrm{ZrO}_{2} / \gamma-\mathrm{Al}_{2} \mathrm{O}_{3}$, catalysts for low temperature selective catalytic reduction of $\mathrm{NO}$ with $\mathrm{NH}_{3}$. Chem. Eng. J. 243, 347-354.

Fang, D., Xie, J.L., Hu, H., Yang, H., He, F., Fu, Z.B., 2015. Identification of $\mathrm{MnO}_{x}$ species and Mn valence states in $\mathrm{MnO}_{x} / \mathrm{TiO}_{2}$ catalysts for low temperature SCR. Chem. Eng. J. 271, 23-30.

Fang, C., Zhang, D., Cai, S., Zhang, L., Huang, L., Li, H., Maitarad, P., Shi, L., Gao, R., Zhang, J., 2013. Low-temperature selective catalytic reduction of $\mathrm{NO}$ with $\mathrm{NH}_{3}$ over nanoflaky $\mathrm{MnO}_{x}$ on carbon nanotubes in situ prepared via a chemical bath deposition route. Nanoscale 5, 9199-9207.

Figueiredo, J.L., Pereira, M.F.R., Freitas, M.M.A., Órfão, J.J.M., 2007. Characterization of active sites on carbon catalysts. Ind. Eng. Chem. Res. 46, 4110-4115.

France, L.J., Yang, Q., Li, W., Chen, Z.H., Guang, J.Y., Guo, D.W., Wang, L.F., Li, X.H., 2017. Ceria modified $\mathrm{FeMnO}_{x}$-enhanced performance and sulphur resistance for lowtemperature SCR of $\mathrm{NO}_{\mathrm{x}}$. Appl. Catal. B-Envion. 206, 203-215.

Gao, X., Liu, S., Zhang, Y., Luo, Z., Cen, K., 2011. Physicochemical properties of metal-doped activated carbons and relationship with their performance in the removal of $\mathrm{SO}_{2}$ and $\mathrm{NO}$. J. Hazard. Mater. 888, 58-66.

Gao, L., Li, C., Zhang, J., Du, X., Li, S., Zeng, J., Yi, Y., Zeng, G., 2018. Simultaneous removal of $\mathrm{NO}$ and $\mathrm{Hg}^{0}$ from simulated flue gas over $\mathrm{CoO}_{x}-\mathrm{CeO}_{2}$ loaded biomass activated carbon derived from maize straw at low temperatures. Chem. Eng. J. 342, 339-349.

Gao, F., Tang, X., Yi, H., Li, J., Zhao, S., Wang, J., Chu, C., Li, C., 2017. Promotional 
mechanisms of activity and $\mathrm{SO}_{2}$ tolerance of $\mathrm{Co}$ - or Ni-doped $\mathrm{MnO}_{x}-\mathrm{CeO}_{2}$ catalysts for SCR of $\mathrm{NO}_{x}$ with $\mathrm{NH}_{3}$ at low temperature. Chem. Eng. J. 317, 20-31.

Grzybek, T., Klinik, J., Motak, M., Papp, H., 2008. Nitrogen-promoted active carbons as catalytic supports, Catal. Today 137, 235-241.

Hadjiivanov, K.I., 2000. Identification of neutral and charged $\mathrm{N}_{x} \mathrm{O}_{y}$ surface species by IR spectroscopy. Catal. Rev. 42, 71-144.

He, L., Weniger, F., Neumann, H., Beller, M., 2016. Synthesis, characterization, and application of metal nanoparticles supported on nitrogen-doped carbon: catalysis beyond electrochemistry, Angew Chem. Int. Ed. 55, 12582-12594.

Jia, J., Zhang, P., Chen, L., 2016. The effect of morphology of $\alpha-\mathrm{MnO}_{2}$ on catalytic decomposition of gaseous ozone. Cataly. Sci. Technol. 6, 5841-5847.

Jia, Y., Xiao, B., Thomas, K.M., 2002. Adsorption of metal ions on nitrogen surface functional groups in activated carbons. Langmuir 18, 470-478.

Jiang, L.J., Liu, Q.C., Ran, G.J., Kong, M., Ren, S., Yang, J., Li, J.L., 2019. V ${ }_{2} \mathrm{O}_{5}$-modified MnCe/AC catalyst with high $\mathrm{SO}_{2}$ tolerance for lowtemperature $\mathrm{NH}_{3}-\mathrm{SCR}$ of $\mathrm{NO}$. Chem. Eng. J. $370,810-821$.

Jiang, L.J., Liu, Q.C., Zhao, Q., Ren, S., Kong, M., Yao, L., Meng, F., 2018. Promotional effect of $\mathrm{Ce}$ on the $\mathrm{SCR}$ of $\mathrm{NO}$ with $\mathrm{NH}_{3}$ at low temperature over $\mathrm{MnO}_{x}$ supported by nitric acidmodified activated carbon. Res. Chem. Intermed. 44, 1729-1744.

Kang, M., Park, E.D., Kim, J.M., Yie, J.E., 2007. Manganese oxide catalysts for $\mathrm{NO}_{x}$ reduction with $\mathrm{NH}_{3}$ at low temperatures. Appl. Catal. A-General 327, 261-269.

Klinik, J., Samojeden, B., Grzybek, T., Suprun, W., Papp, H., Gläser, R., 2011. Nitrogen 
promoted activated carbons as $\mathrm{DeNO}_{x}$ catalysts. 2 . The influence of water on the catalytic performance. Catal. Today 176, 303-308.

Knoblauch, K., Richter, E., Jüntgen, H., 1981. Application of active coke in processes of $\mathrm{SO}_{2}$ and $\mathrm{NO}_{\mathrm{x}}$ removal from flue gases. Fuel 60, 832-838.

Li, S., Wang, X., Tan, S., Shi, Y., Li, W., 2017. $\mathrm{CrO}_{3}$ supported on sargassum-based activated carbon as low temperature catalysts for the selective catalytic reduction of $\mathrm{NO}$ with $\mathrm{NH}_{3}$. Fuel 191, 511-517.

Liang, P., Zhang, C., Duan, X., Sun, H., Liu, S., Tade, M.O., Wang, S., 2017. N-doped graphene from metal-organic frameworks for catalytic oxidation of p-hydroxylbenzoic acid: $\mathrm{N}$ functionality and mechanism. ACS Sustainable Chem. Eng. 5, 2693-2701.

Lu, P., Li, R., Xing, Y., Li, Y., Zhu, T., Yue, H., Wu, W., 2018. Low temperature selective catalytic reduction of $\mathrm{NO}_{x}$ with $\mathrm{NH}_{3}$ by activated coke loaded with $\mathrm{Fe}_{x} \mathrm{Co}_{y} \mathrm{Ce}_{z} \mathrm{O}_{m}$ : The enhanced activity, mechanism and kinetics. Fuel 233, 188-199.

Peña, D.A., Uphade, B.S., Reddy, E.P., Smirniotis, P.G., 2004. Identification of surface species on titania-supported manganese, chromium, and copper oxide low-temperature SCR catalysts. J. Phys. Chem. B 108, 9927-9936.

Prahas, D., Kartika, Y., Indraswati, N., Ismadji, S., 2008. Activated carbon from jackfruit peel waste by $\mathrm{H}_{3} \mathrm{PO}_{4}$ chemical activation: Pore structure and surface chemistry characterization. Chem. Eng. J. 140, 32-42.

Qi, G., Yang, R., Chang, R., 2004. $\mathrm{MnO}_{x}-\mathrm{CeO}_{2}$ mixed oxides prepared by co-precipitation for selective catalytic reduction of $\mathrm{NO}$ with $\mathrm{NH}_{3}$ at low temperatures. Appl. Catal. B-Environ. 51, 93-106. 
Qiu, X., Xiao, Z., Wang, L., Fan, L., 2018. High rate integrated quasi-solid state supercapacitors based on nitrogen-enriched active carbon fiber/reduced graphene oxide nanocomposite. Carbon 130, 196-205.

Ramis, G., Busca, G., Bregani, F., Forzatti, P., 1990. Fourier transform-infrared study of the adsorption and co-adsorption of nitric oxide, nitrogen dioxide and ammonia on vanadiatitania and mechanism of selective catalytic reduction. Appl. Catal. 64, 259-278.

Ren, S., Guo, F., Yang, J., Yao, L., Zhao, Q., Kong, M., 2017. Selection of carbon materials and modification methods in low-temperature sintering flue gas denitrification. Chem. Eng. Res. Des. 126, 278-285.

Ruiz, J.C.S., Fernandez, E.V.R., Albero, J.S., Escribano, A.S., Reinoso, F.R., 2008. Preparation and characterization of $\mathrm{CeO}_{2}$ highly dispersed on activated carbon. Mater. Res. Bull. 43, $1850-1857$.

Shi, R., Zhao, J., Liu, S., Sun, W., Li, H., Hao, P., Li, Z., Ren, J., 2018. Nitrogen-doped graphene supported copper catalysts for methanol oxidative carbonylation: Enhancement of catalytic activity and stability by nitrogen species. Carbon 130, 185-195.

Shirahama, N., Moon, S.H., Choi, K.H., Enjoji, T., Kawano, S., Korai, Y., Tanoura, M., Mochida, I., 2002. Mechanistic study on adsorption and reduction of $\mathrm{NO}_{2}$ over activated carbon fibers. Carbon 40, 2605-2611.

Sousa, J.P.S., Pereira, M.F.R., Figueiredo, J.L., 2012. NO oxidation over nitrogen doped carbon xerogels. Appl. Catal. B-Environ. 125, 398-408.

Strelko, V.V., Kuts, V.S., Thrower, P.A., 2000. On the mechanism of possible influence of heteroatoms of N, B and S in a carbon matrix on the catalytic activity. Carbon 38, 1499- 
1524.

Su, Y., Fan, B., Wang, L., Liu, Y., Huang, B., Fu, M., Chen, L., Ye, D., 2013. MnO $_{x}$ supported on carbon nanotubes by different methods for the SCR of $\mathrm{NO}$ with $\mathrm{NH}_{3}$. Cataly. Today $201,115-121$

Sultana, A., Sasaki, M., Hamada, H., 2012. Influence of support on the activity of Mn supported catalysts for SCR of NO with ammonia. Catal. Today 185, 284-289.

Sun, P., Guo, R., Liu, S., Wang, S., Pan, W., Li, M., 2017. The enhanced performance of $\mathrm{MnO}_{x}$ catalyst for $\mathrm{NH}_{3}-\mathrm{SCR}$ reaction by the modification with Eu. Appl. Catal. A-General 531, $129-138$.

Tang, X., Hao, J., Xu, W., Li, J., 2007. Low temperature selective catalytic reduction of $\mathrm{NO}_{x}$ with $\mathrm{NH}$ over amorphous $\mathrm{MnO}_{x}$ catalysts prepared by three methods. Cataly. Commun. 8, $329-334$

Wang, J., Yan, Z., Liu, L., Zhang, Y., Zhang, Z., Wang, X., 2014a. Low-temperature SCR of $\mathrm{NO}$ with $\mathrm{NH}_{3}$ over activated semi-coke composite-supported rare earth oxides. Appl. Surf. Sci. 309, 1-10.

Wang, J., Yan, Z., Liu, L., Chen, Y., Zhang, Z., Wang, X., 2014b. In situ DRIFTS investigation on the SCR of $\mathrm{NO}$ with $\mathrm{NH}_{3}$ over $\mathrm{V}_{2} \mathrm{O}_{5}$ catalyst supported by activated semi-coke. Appl. Surf. Sci. 313, 660-669

Wang, L., Cheng, X., Wang, Z., Ma, C., Qin, Y., 2017. Investigation on Fe-Co binary metal oxides supported on activated semi-coke for NO reduction by CO. Appl. Catal. B-Environ. 201, 636-651.

Wang, X., Zhu, Y., Xu, Z., Liu, X., Zhang, Y., 2014c. Low-temperature selective catalytic 
reduction of $\mathrm{NO}$ over $\mathrm{MnO}_{x} / \mathrm{CNTs}$ catalysts: Effect of thermal treatment condition. Catal. Comm. 50, 34-37.

Wang, Y., Zhou, Y., Shen, Y., Zhu, S., 2018. Pyridinic N: A special group for enhancing direct decomposition reaction of $\mathrm{NO}$ over $\mathrm{N}$-doped porous carbon, Microporous and Mesoporous Mater. 265, 98-103.

Wang, L., Huang, B., Su, Y., Zhou, G., Wang, K., Luo, H., Ye, D., 2012. Manganese oxides supported on multi-walled carbon nanotubes for selective catalytic reduction of NO with $\mathrm{NH}_{3}$ : Catalytic activity and characterization. Chem. Eng. J. 192, 232-241.

Wang, M., Liu, H., Huang, Z., Kang, F., 2014d. Activated carbon fibers loaded with $\mathrm{MnO}_{2}$ for removing NO at room temperature. Chem. Eng. J. 256, 101-106.

Wang, D., Jang, J.Y., Liu, Y., Sharma, M.K., Luo, J., Li, J., Kamasamudram, K., Epling, W.S., 2015. A comparison of hydrothermal aging effects on $\mathrm{NH}_{3}-\mathrm{SCR}$ of $\mathrm{NO}_{x}$ over $\mathrm{Cu}-\mathrm{SSZ}-13$ and Cu-SAPO-34 catalysts. Appl. Catal. B-Environ. 165, 438-445.

Watanabe, H., Asano, S., Fujita, S.I., Yoshida, H., Arai, M., 2015. Nitrogen-doped, Metal-free activated carbon catalysts for aerobic oxidation of alcohols. ACS Catal. 5, 2886-2894.

Yan, Z., Qu, Y., Liu, L., Ge, X., Yang, J., Wei, L., Yang, T., Wang, X., 2017. Promotional effect of rare earth-doped manganese oxides supported on activated semi-coke for selective catalytic reduction of $\mathrm{NO}$ with $\mathrm{NH}_{3}$. Environ. Sci. Pollut. Res. Int. 24, 24473-24484.

Yang, J., Ren, S., Zhang, T.S., Su, Z.H., Long, H.M., Kong, M., Yao, L., 2020. Iron doped eff ects on active sites formation over activated carbon supported Mn-Ce oxide catalysts for low-temperature SCR of NO. Chem. Eng. J. 379, 122398.

Yang, L., Jiang, W., Yao, L., Jiang, X., Li, J., 2017. Suitability of pyrolusite as additive to 
activated coke for low-temperature NO removal. J. Chem. Technol. Biotechnol. 93, 690697.

Yao, L., Ren, S., Liu, Q.C., Yang, J., Jiang, L., Fan, C., Chen, D.Y., 2019. Role of nitrogen functional groups and manganese oxides on the reduction of $\mathrm{NO}$ over modified semi-coke catalyst at low temperature. Res. Chem. Intermed. 45, 563-579.

You, F., Yu, G., Wang, Y., Xing, Z., Liu, X., Li, J., 2017. Study of nitric oxide catalytic oxidation on manganese oxides-loaded activated carbon at low temperature. Appl. Surf. Sci. 413, $387-397$.

You, X.C., Sheng, Z.Y., Yu, D.Q., Yang, L., Wang, S., 2017. Influence of Mn/Ce ratio on the physicochemical properties and catalytic performance of graphene supported $\mathrm{MnO}_{x}-\mathrm{CeO}_{2}$ oxides for $\mathrm{NH}_{3}$-SCR at low temperature. Appl. Surf. Sci. 423, 845-854.

Yu, C., Huang, B., Dong, L., Chen, F., Liu, X., 2017. In situ FT-IR study of highly dispersed $\mathrm{MnO}_{x} / \mathrm{SAPO}-34$ catalyst for low-temperature selective catalytic reduction of $\mathrm{NO}_{x}$ by $\mathrm{NH}_{3}$, Catal. Today 281, 610-620.

Zhang, H. Sun, H., Zhao, K., Han, Y., Wu, J., Jiao, T., Liang, P., 2018. Influences of water vapor and fly ash on elemental mercury removal over cerium-oxide-modified semi-coke. Fuel $217,211-217$.

Zhang, P., Yan, S., Wei, S., Wei, Y., Jia, L., 2016. Low-temperature selective catalytic reduction of $\mathrm{NO}$ with $\mathrm{NH}_{3}$ over Ni-Mn-O $x$ catalysts. RSC Adv. 6, 107270-107277.

Zhao, Z., Fan, J., Liu, W., Xue, Y., Yin, S., 2017. In-situ hydrothermal synthesis of $\mathrm{Ag}_{3} \mathrm{PO}_{4} / \mathrm{g}-$ $\mathrm{C}_{3} \mathrm{~N}_{4}$ composite and their photocatalytic decomposition of $\mathrm{NO}_{x}$. J. Alloy. Compd. 695, 2812-2819. 
Zhu, Z., Liu, Z., Liu, S., Niu, H., 2000. Adsorption and reduction of NO over activated coke at low temperature. Fuel 79, 651-658. 